\title{
Molecular biology of the blood-brain and the blood-cerebrospinal fluid barriers: similarities and differences
}

Zoran Redzic

\begin{abstract}
Efficient processing of information by the central nervous system (CNS) represents an important evolutionary advantage. Thus, homeostatic mechanisms have developed that provide appropriate circumstances for neuronal signaling, including a highly controlled and stable microenvironment. To provide such a milieu for neurons, extracellular fluids of the CNS are separated from the changeable environment of blood at three major interfaces: at the brain capillaries by the blood-brain barrier (BBB), which is localized at the level of the endothelial cells and separates brain interstitial fluid (ISF) from blood; at the epithelial layer of four choroid plexuses, the bloodcerebrospinal fluid (CSF) barrier (BCSFB), which separates CSF from the CP ISF, and at the arachnoid barrier. The two barriers that represent the largest interface between blood and brain extracellular fluids, the BBB and the BCSFB, prevent the free paracellular diffusion of polar molecules by complex morphological features, including tight junctions (TJs) that interconnect the endothelial and epithelial cells, respectively. The first part of this review focuses on the molecular biology of TJs and adherens junctions in the brain capillary endothelial cells and in the CP epithelial cells. However, normal function of the CNS depends on a constant supply of essential molecules, like glucose and amino acids from the blood, exchange of electrolytes between brain extracellular fluids and blood, as well as on efficient removal of metabolic waste products and excess neurotransmitters from the brain ISF.

Therefore, a number of specific transport proteins are expressed in brain capillary endothelial cells and CP epithelial cells that provide transport of nutrients and ions into the CNS and removal of waste products and ions from the CSF. The second part of this review concentrates on the molecular biology of various solute carrier (SLC) transport proteins at those two barriers and underlines differences in their expression between the two barriers. Also, many blood-borne molecules and xenobiotics can diffuse into brain ISF and then into neuronal membranes due to their physicochemical properties. Entry of these compounds could be detrimental for neural transmission and signalling. Thus, BBB and BCSFB express transport proteins that actively restrict entry of lipophilic and amphipathic substances from blood and/or remove those molecules from the brain extracellular fluids. The third part of this review concentrates on the molecular biology of ATP-binding cassette (ABC)-transporters and those SLC transporters that are involved in efflux transport of xenobiotics, their expression at the BBB and BCSFB and differences in expression in the two major blood-brain interfaces. In addition, transport and diffusion of ions by the BBB and CP epithelium are involved in the formation of fluid, the ISF and CSF, respectively, so the last part of this review discusses molecular biology of ion transporters/exchangers and ion channels in the brain endothelial and CP epithelial cells.
\end{abstract}

Correspondence: redzic@hsc.edu.kw

Department of Physiology, Faculty of Medicine, Kuwait University, SAFAT

13110, Kuwait 


\section{Introduction}

A constant and well-controlled composition of the extracellular fluid in the central nervous system (CNS) is essential for efficient neuronal processing. Invertebrate nervous systems, which are far less complex than the mammalian brain, are protected from fluctuations in composition of body fluids by a barrier that is formed by glial cells and this arrangement also applies to some ancestral vertebrates. With the CNS becoming more complex during evolution, an endothelial barrier appeared, giving a strong selective advantage. Consequently, all existing vertebrates, except for a few fish species, have endothelial blood-brain barriers (BBB).

The $\mathrm{BBB}$ and the blood-cerebrospinal fluid barrier (BCSFB) are formed by brain endothelial cells (BECs) and choroid plexus $(\mathrm{CP})$ epithelial cells, respectively. The BBB and the BCSFB are not only anatomical barriers, but also dynamic tissues that express multiple transporters, receptors and enzymes. Brain capillaries are closely associated with perivascular astrocytic endfeet, pericytes and microglia that influence BBB permeability and, together with brain endothelial cells, constitute a "neurovascular unit".

The two main functions of these barriers are to impede free diffusion between brain fluids and blood and to provide transport processes for essential nutrients, ions and metabolic waste products. Hence, the aim of this review is to address similarities and differences in the molecular biology of cellular junctions, solute carrier transporters, ATP-binding cassette transporters and ion transporters at the BBB and the BCSFB.

\section{Morphology of the BBB and BCSFB}

Although there are several similar features between the blood-brain barrier (BBB) and the blood-cerebrospinal fluid barrier (BCSFB), it should be kept in mind that the cellular basis of these two structures as well as their primary functions differ: BBB is located in brain capillaries and, thus, it is an endothelial structure with its main role to protect the brain from physiological fluctuations in plasma concentrations of various solutes and from blood-borne substances that could interfere with neurotransmission, but at the same time to provide mechanisms for exchange of nutrients, metabolic waste products, signaling molecules and ions between the blood and the brain ISF. In contrast to this, the BCSFB is created by a layer of a modified cuboidal epithelium, the CP, that secretes cerebrospinal fluid (CSF) and this process could be considered as main function of this epithelium. The differences in principal function are related to differences in morphology and molecular biology.
Brain capillaries express complex morphology that provide the restrictive characteristics of the endothelial layer with regard to diffusion of solutes; this is an essential feature to protect the brain from unwanted solutes from blood with tight junctions $(\mathrm{Tjs})$ that interconnect adjacent endothelial cells and occlude the paracellular spaces. In addition, BECs show low pinocytotic activity and the endothelium is further secluded by a layer of astrocytic end feet and pericytes on the brain side that place additional restrictions on permeability. Thus, the $\mathrm{BBB}$ in vivo provides high resistance to movement of ions, with transendothelial electrical resistance (TEER) being in the range of $1500 \Omega \mathrm{cm}^{2}$ (pial vessels), which is quite high when compared to TEER of $3-33 \Omega \mathrm{cm}^{2}$ in other tissues [1]. The total capillary surface area in the brain is about $100-150 \mathrm{~cm}^{2} \mathrm{~g}^{-1}$ [2], which when estimated for the whole brain approximates $20 \mathrm{~m}^{2}$ [3], suggesting that the BBB can be considered as a large and thin membrane, providing ideal conditions for exchange processes between blood and brain interstitial fluid (ISF). When considering the total area available for exchange, it should be noted that brain capillaries are perfused all the time, but they shift to high blood flow with an increase in cerebral blood flow (CBF), or to low blood flow with a decrease in CBF [4].

Choroid plexuses are villous structures floating in the CSF and attached to the ventricular ependyma by a stalk. The ependyma is continuous with the epithelial layer of the $\mathrm{CP}$ which is composed of a single layer of cells filled with mitochondria and joined together by tight TJs (Figure 1) [5]. The TEER offered by these TJs cannot be measured in vivo in most animals. However, in vitro measurements using the single-sided fourth ventricle CP of the bull frog maintained in an Ussing chamber suggested values of about $150 \Omega \mathrm{cm}^{2}$ [6], much less than the resistance of the BBB. The low value of TEER would suggest that the CPs fall into the class of leaky epithelia, similar to some segments of the kidney and gut, which form an isotonic fluid and do not generate steep transepithelial concentration gradients across the tissues [7]. These leaky epithelia can secrete large volumes of fluid but use relatively little energy for this process. CP epithelial cells posses a dense apical coat of microvilli, while kinocilia are rarely found; in contrast to this, the apical surface of ventricular ependymal cells demonstrates a large number of kinocilia [8], with rare microvilli of variable size. Between the lateral walls of the CP epithelial cells are complex interdigitations particularly apparent close to the blood side of the tissue laying on a basal lamina that demarcate the inner stroma of a highly vascularized connective tissue; these interdigitations expand the surface area of the CP [9]. 


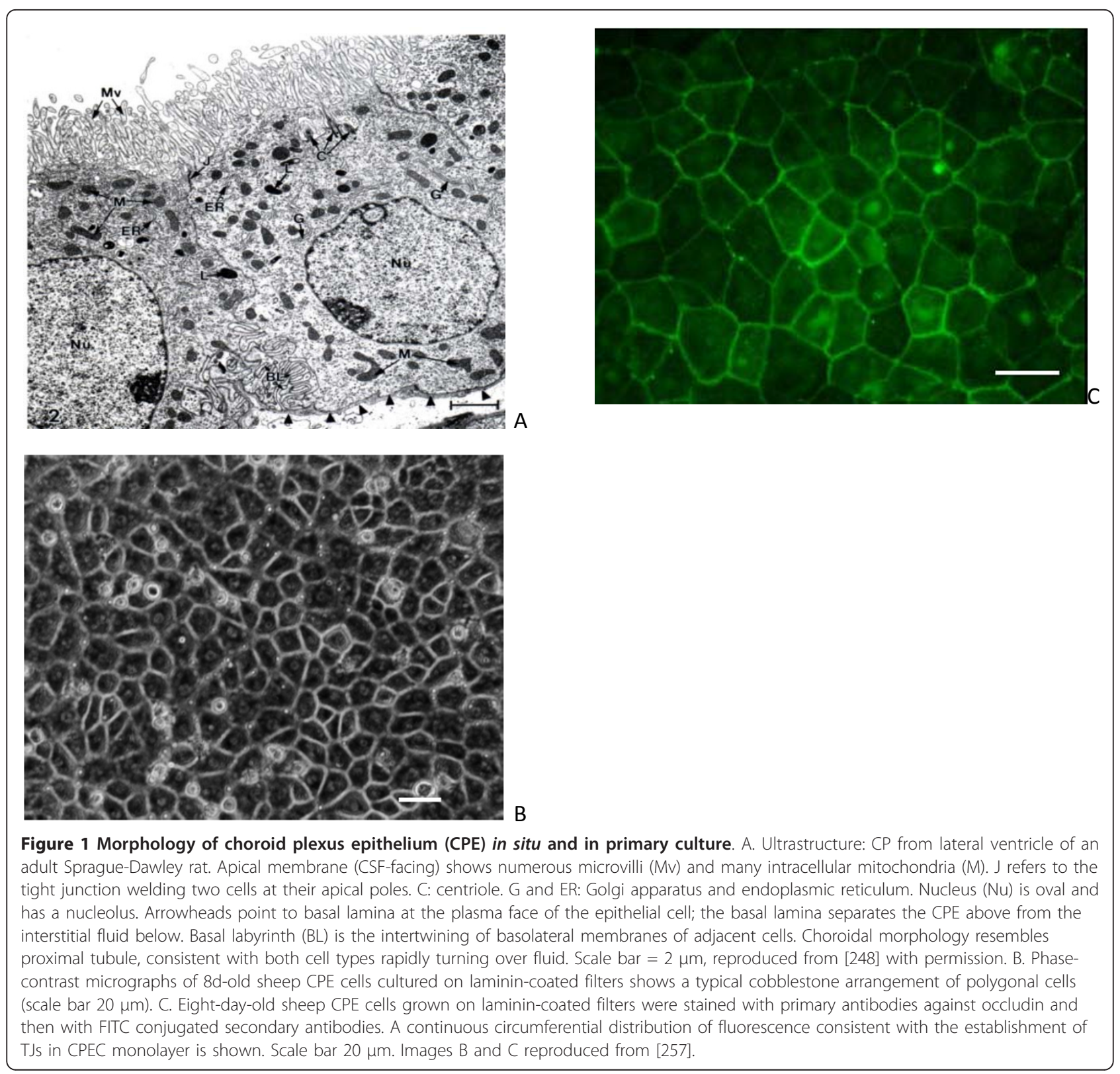

\section{Molecular biology of cell junctions at the BBB and BCSFB}

Brain endothelial cells (BECs) and CP epithelial (CPE) cells are connected at a junctional complex by the TJ and adherens junctions (AJ) [10]. BECs also express gap junctions but their functional significance is not clear. All $\mathrm{TJ}$ and $\mathrm{AJ}$ are composed of transmembrane proteins and cytoplasmic plaque proteins; plaque proteins cluster integral TJ proteins and form a platform for interaction with scaffolding and signaling proteins. In addition, a circumferential actin belt that encircles each endothelial/epithelial cell at the level of TJs is important for formation and normal function of TJs.

\section{Protein structure of tight junctions}

Transmembrane proteins of the TJ include occludin, claudins and junctional adhesion molecules (JAM)-A, B and $C$ [11,12] (Figure 2). Occludin structure appears to be essential for normal occluding function of TJs in both BBB and BCSFB. Occludin possesses two extracellular loops, four trans-membrane domains and three cytoplasmic domains; the cytoplasmic domains include one intracellular short turn, $\mathrm{N}$-terminal domain and a 150 amino-acids long carboxyl (C-) -terminal domain [12,13] (Figure 2). Extracellular loops provide the gatelike structure of TJs; it is believed that second loop mainly determines the TEER [14]. The C-terminal 


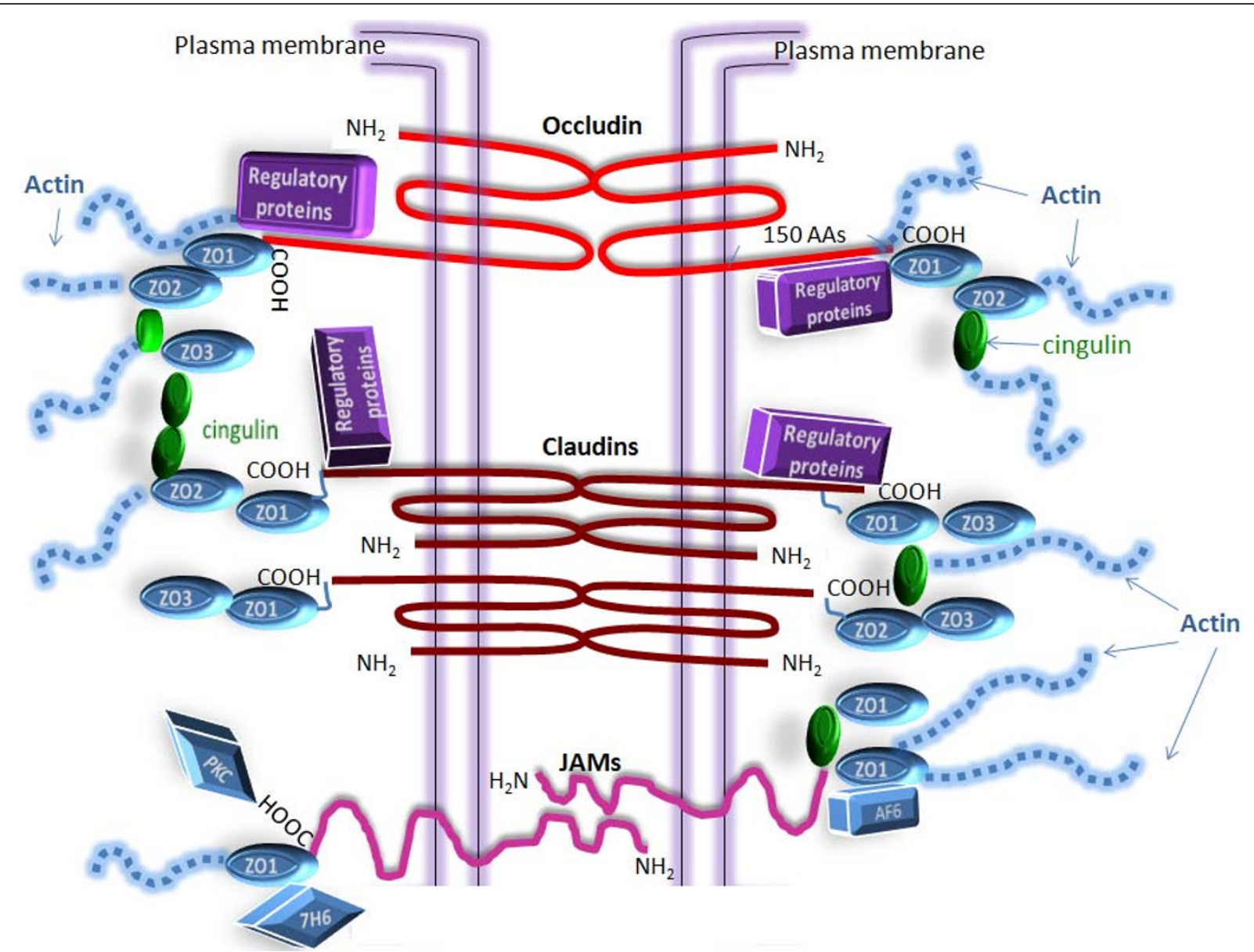

Figure 2 Schematic representation of tight junctions between two adjacent cells. In general, TJs at the BBB and in the CP epithelium are similar, but they express different claudins (that are not shown in this figure). This is probably an important structural difference underlying the lower values of TEER across CP epithelium compared to TEER values across the brain endothelium.

domain associates with zonulla occludens proteins $(\mathrm{ZO})$ $-1, \mathrm{ZO}-2$ and $\mathrm{ZO}-3$ and interacts with regulatory proteins, such as protein kinase $C$, tyrosine kinase and phosphoinositide 3-kinase [12,15]. Both occludin and claudins are phospho-proteins that change conformation upon phosphorylation/dephosphorylation of the side chain hydroxyl group, which affects interaction with other proteins; therefore, regulatory proteins mainly posses kinase or phosphatase activities. Dephosphorylation of occludin causes disassembly of its association with ZO proteins. Deletion of occludin in mice results in postnatal growth retardation, although the TJs themselves appear to function normally [16], which suggests that other TJ proteins compensate for the lack of occludin. Occludin deletion from embryonic stem cells did not prevent differentiation of these cells into polarized epithelial cells with clear TJs [17]. The N-terminal part of occludin has an important role in a TJ assembly; this activity was revealed by an experiment in which abnormal occludin that lacks $\mathrm{N}$-terminal domain caused a damaging effect on the $\mathrm{TJ}$ function of endothelial cell monolayers in vitro. Those monolayers failed to develop high TEER and developed increased paracellular diffusion of small polar molecules [18]. Occludin is also subject to endocytic recycling with two proteins associated to TJs, a member of the Rab family G-proteins, Rab13, and a Rab13-binding protein, MICAL-L2 (molecule interacting with CasL-like 2) mediating the specific endocytic recycling of occludin (but not other membrane proteins, like transferrin receptor), which is important for maintenance of functional TJs [19]. A study has revealed that in Alzheimer's disease (AD) and in vascular dementia there were significantly more occludin-positive astrocytes and oligodendrocytes in the frontal white matter than in age-matched controls [20], which may indicate autophagy of $\mathrm{TJ}$ proteins by the surrounding glial cells.

Claudins are the principal barrier-forming proteins, which include a multigene family consisting of at least 24 members in mammals and are an essential structural 
component of TJ strands. All claudins show the same structural pattern: four membrane-spanning regions, two extracellular loops and two cytoplasmic domains, a short $\mathrm{N}$-terminal sequence and a long C-terminal sequence [21] (Figure 2). Two neighboring claudins from two adjacent cells form TJ strands through homophilic claudin-claudin interactions [22]. Extracellular loops determine paracellular charge selectivity, so each type of claudin regulates the diffusion of a group of molecules of a certain size. Deletion of claudin 5 in mice showed detrimental effects on the brain causing early death; those effects were due to a size-selective loosening of the BBB for molecules with $\mathrm{MW}<800 \mathrm{Da}$ [23]. The claudin C-terminus binds cytoplasmic proteins, particularly ZO-1, ZO-2, and ZO-3 [24] (Figure 2). Proper interaction of claudins is essential to selectively limit paracellular ion movement, an action which produces the high TEER of the BBB. It appears that the differences in claudin content between the two barriers play an important role in the observed differences in TEERs between the BBB and the BCSFB [25,26]: claudins $3,5,12$ and probably 1 are present at the $\mathrm{BBB}$ $[10,23]$, while claudin $1,2,3$ and 11 are expressed in the CP epithelium [27]. It was initially believed that claudin1 was the most abundant $\mathrm{TJ}$ protein in the CPE and a marker of CP TJs [27]; this was later realized to be an artifact due to a cross-reaction of the anti-claudin-1 antibodies with claudin-3; it appears that claudin-3 is the most abundant claudin in CPE [28].

It was known from Goldman's second experiment [29] that the lining of the ventricular walls, which consists of a layer of ependymal cells, does not restrict diffusion of solutes. The molecular basis for this is that ependymal cells in mammals do not express TJs [30]. However, complex TJs were described in some fish and amphibia $[31,32]$. Also, it was reported in mammalian brain during embryonic development that the ependymal cell layer forms cellular junctions similar to TJs and provides this layer with barrier properties [33]. This might indicate that disappearance of this CSF-brain barrier could be related to the development of the more effective epithelial BCSFB in adult mammals.

JAMs A,-B and C are members of the immunoglobulin superfamily that have a membrane-spanning domain, an extracellular domain, an extracellular N-terminus, and a cytoplasmic C-terminus [34] (Figure 2). JAMs are expressed at the intracellular junctions of BECs and CPEs and have different patterns of homophilic and heterophilic interactions with JAM molecules on the adjacent cell, forming dimers that are part of the tight junction structure [35]. The short $C$ terminal tail contains a domain which mediates interactions with ZO-1, cingulin, junction-associated protein AF6, tight-junction-associated protein antigen $7 \mathrm{H} 6$ and scaffold proteins [36] and also includes phosphorylation sites that may serve as substrates for protein kinase C (PKC) [37]. It is believed that JAMs are involved in the localization of ZO-1 and occludin in TJ complexes [34]. Transmembrane TJ proteins are linked to the cytoskeleton by scaffolding $\mathrm{ZO}$ proteins 1, 2 and 3 in BECs and in CPE $[10,30]$. These proteins belong to a family of membrane-associated guanylate kinase proteins. ZO proteins provide the cytoskeletal anchorage for the $\mathrm{TJ}$ proteins and are also involved in control of spatial distribution of claudins. Cingulin is a myosin-like protein that binds preferentially to ZO proteins at the globular head, to other cingulin molecules at the tail and to actin. Actin has known binding sites on all of the $\mathrm{ZO}$ proteins, on claudin, occludin and cingulin [38].

A study on rat $B B B$ that used serial analysis of gene expression (SAGE) provided a comprehensive gene expression profile of rat BECs from freshly-collected brain microvasculature and has revealed that the SAGE tag for claudin 5 was $16^{\text {th }}$ of the 50 most abundant tags enriched in BECs [39] with a relative abundance in rat BEC SAGE catalog 52 tags/100.000. Other TJ protein transcripts were less abundant: claudin 11 (18/100.000), ZO-2 (11/100.000) and ZO-1 (3/100.000) and they were not among the 50 most abundant tags enriched in BECs [39].

Through interactions with other proteins and/or as a consequence of cell signaling, $\mathrm{TJ}$ s in the brain are dynamic structures; spatial distributions of proteins can be changed under various circumstances. Effects of signaling on TJ expression and integrity have been studied for pathophysiological conditions, including cerebral ischemia in vivo, conditions that mimic ischemia in vitro and inflammation. Claudin 5 expression was reduced and localization in BECs altered by hypoxia in vitro; changes were accompanied by a decrease in TEER [40]. A decrease in occludin and ZO-1 expression in BECs after cerebral embolism has been reported [41] and localization of occludin, $\mathrm{ZO}-1$, and $\mathrm{ZO}-2$ proteins was altered after hypoxia in vitro [42]. In addition, ZO-1 and $\mathrm{ZO}-2$ shifted to the nucleus during hypoxia in vitro, a relocation that was accompanied by increased paracellular permeability [43]. Recent studies have also revealed an important role of transforming growth factor (TGF)$\beta$-signaling in expression of TJ proteins claudin-5, occludin and ZO-1 [44]. These studies showed that peripheral inflammatory pain caused a reduction in serum TGF- $\beta 1$ and protein expression of the TGF- $\beta$ receptor, activin receptor-like kinase-5 (ALK5), in the brain; changes were accompanied by increased expression of TJ proteins and increased paracellular permeability of the BBB [44]. The same effects were produced by pharmacological inhibition of ALK5, which indicated that TGF- $\beta$ / ALK5 signaling was involved in the regulation of TJ 
protein expression and/or their spatial distribution [44]. Also, oxidative stress produced during hypoxia and reoxygenation mediated an increase in BBB paracellular permeability, probably because of alterations in the localization of occludin, with movement of occludin away from the TJ [45]. Protein kinase C (PKC) is involved in control of TJ expression in BECs and it was shown that $\mathrm{PKC}$ isoenzyme $\mathrm{nPKC}$-theta signaling mediated $\mathrm{TJ}$ protein rearrangement, resulting in increased BBB paracellular permeability [46]. A study on cell culture - induced changes in the blood-brain barrier transcriptome in mice by qPCR has revealed that there was a dramatic drop in the relative amount of mRNA for claudin 5 and occludin in single cultured cells, in cells co-cultured with astrocytes and in immortalized cell line, when compared to non-cultured and freshly isolated mouse BECs [47]. This finding could explain fairly low TEER values in BEC cell cultures, when compared to TEER of BECs in vivo.

\section{Adherens Junctions}

Adherens junctions (AJs) are specialized cell-cell junctions that are formed by cadherins and associated proteins into which actin filaments are inserted. Optimal function of cadherins requires association of their $\mathrm{C}$ terminus with catenins; cadherins bind directly to $\beta$-catenin and to p120 catenin, which can bind to $\alpha$-catenin, a protein that in turn binds actin [48]. In endothelial cells, vascular endothelial (VE) cadherin is present [35,49]; however, a study has shown that barrier-forming endothelium (i.e. BECs) and barrier-forming epithelium (i.e. CPE) mainly expressed cadherin-10, while the expression of VE cadherin was scarce [50]. On the other hand, brain microvessels that do not have BBB properties (i.e. in the circumventricular organs and CP capillaries) expressed only VE-cadherin and did not express cadherin-10 [50]. Also, in the microvessels of glioblastoma multiforme tumors, which lose BBB properties, VE-cadherin was expressed instead of cadherin-10 [50]. These findings suggest that cadherin-10 has an important role in the development and maintenance of the $\mathrm{BBB}$ and the BCSFB. Cadherins regulate endothelial functions by direct activation of phosphoinositide 3kinase, a signaling system that has a role in organization of the cytoskeleton and forms complexes with the vascular endothelial growth factor (VEGF) receptor 2. Thus, cadherin-mediated signaling is important for endothelial cell layer integrity and for the spatial organization of new vessels [51]. At least four catenins, $\beta, \alpha, \chi$ and $\mathrm{p} 120$ are expressed at the BBB, with $\beta$-catenin linking the cadherin to $\alpha$-catenin which binds the complex to the actin network of the cell skeleton [49]. However, a study has challenged this view, since it was unable to confirm actin binding to a preformed E-cadherin- $\beta$ - catenin- $\alpha$-catenin complex [52]. As mentioned above, CPE expresses cadherin-10 while CP capillaries express VE-cadherin [50]. Only two catenins, $\alpha$ and $\beta$, have been detected in the $\mathrm{CP}$ epithelium so far, with $\alpha$-catenin binding to the actin network [52].

In summary, BECs and $\mathrm{CP}$ epithelium show many similarities in the organization of Ts and AJs; the main difference is that the CPE provides a barrier that offers lower TEER values and is less restrictive than the BBB. The molecular organization underlying that difference is probably related to expression of different claudins, since those proteins play an important role in barrier size-selectivity and selectivity to paracellular movement of ions.

\section{Molecular biology of transport processes between blood and brain extracellular fluids}

TJs restrict paracellular diffusion across cellular layers. Thus, hydrophilic molecules cannot readily enter brain ISF or CSF by simple diffusion and must be transferred across the layer by transcellular routes. On the other hand, lipid soluble non-polar molecules can easily diffuse into lipid bilayers and thus affect the composition of cellular membranes. The later process could have a detrimental impact on brain function. Thus, the BBB and the BCSFB have, in general, a similar functional organization with regard to transport of molecules: they express various proteins in their membranes that either use carrier-mediated transcellular transport of solutes, maintaining optimal composition of the brain ISF, or use ATP-driven efflux of lipophilic molecules, the latter process having an important role in maintenance of lipid bilayers in brain cells [53].

Proteins that mediate transport of solutes not directly coupled to ATP hydrolysis belong to a superfamily of solute carriers (SLC); this family includes facilitated transporters, ion-coupled transporters and exchangers that do not require ATP. They facilitate membrane transport of monosaccharides [54], amino-acids [55], monocarboxylic acids [56], vitamins [57], nucleosides [58,59], purine [60] and pyrimidine [61] bases, ions and amphipathic molecules (organic anions and organic cations). The second superfamily consists of ATP-binding cassette $(\mathrm{ABC})$ proteins that directly couple efflux transport of molecules from a lipid bilayer against the concentration gradient to ATP hydrolysis [53]. Due to the presence of $\mathrm{ABC}$-transporters, a large number of solutes and xenobiotics have a much lower transfer rate into the CNS than might be expected from their lipophilicity, which is expressed as $\log \mathrm{D}$ octanol/buffer partition coefficient at $\mathrm{pH}$ 7.4.

There are large dissimilarities between the $\mathrm{BBB}$ and the BCSF in regard to expression of SLCs and $A B C$ transporters. Also, some of these transport proteins are 
expressed in both membranes of the two barriers, in the one that faces brain fluids and in the one that faces blood/CP ISF; other transport proteins are inserted into either the luminal or abluminal membrane only.

\section{Glucose transporters}

Glucose is the principal energy source for mammalian brain and a continuous supply of this substrate is essential to maintain normal cerebral function [62]. The brain rapidly catabolizes glucose, which creates a downhill gradient for this hexose from blood towards the brain ISF and glucose transport into brain is mediated by facilitative glucose transporter proteins. Delivery of glucose from the blood to the brain requires transport across the endothelial cells of the blood-brain barrier and across the plasma membranes of neurons and glia. There are also several lines of evidences indicating metabolic coupling between astrocytes and neurons, whereby glucose is used and lactate is released into the ISF by the astrocytes $[63,64]$. Lactate is then taken up by neurons, where it serves as an important fuel. Astrocytes appear to form the first cellular barrier that glucose faces when entering the brain and they are ideally located to provide coupling between neuronal activity and glucose uptake.

Several isoforms of equilibrative glucose transporters, GLUT, have been identified in the brain, which included GLUT1 (Human Genome Organization, HUGO, name SLC2A1) [65], 3 (SLC2A3) [66] and 8 (SLC2A8) [67]. GLUT 1 is a ubiquitous glucose transporter in mammalian cells and it is abundant in the brain; also it is exclusively expressed at the $\mathrm{BBB}$, especially at its abluminal membrane and in CPE cells (Figure 3A, B) [62]. Thus, not surprisingly, a rat blood-brain barrier transcriptome study revealed that GLUT1 tag was within 15 of the most abundant tags enriched in rat brain microvessels, together with tags that corresponded to mRNA encoding P-glycoprotein (P-gp), transferrin receptor and the thyroid hormone transporter Oatp1c1. It was also the most abundant tag when compared to tags identifying other solute-carrier family members, indicating the importance of glucose transport at the BBB for brain homeostasis [39]. With regard to this study, it should be noted that at least several tags out of those top- 15 were in fact associated with genes expressed in reticulocytes (like hemoglobin $\beta$ chain), which was probably due to contamination of brain microvessels with red blood cells [39]. GLUT1 has molecular weight (MW) which can range between $45 \mathrm{kDa}$ (smaller MW species) to $55 \mathrm{KDa}$ (larger MW species) [68].

Most parameters for GLUT1 kinetics have been determined in red blood cells and Xenopus oocytes at subphysiological temperatures $\left(20^{\circ} \mathrm{C}\right)$ using zero-trans flux estimation that revealed $\mathrm{Km}$ for glucose 1.6-4.6 $\mathrm{mM}$ and
16.9-26.2 mM (equal exchange method) [69]. However, a recent study using a multicompartmental data analysis on BECs in culture revealed a $\mathrm{Km}$ of 1.5-3.5 mM [70]. The larger MW species are present in microvessels [71], the smaller species are present in neurons and glial cells and the intermediate species in the CPE [72]. The different molecular weights are associated with differences in $\mathrm{N}$-linked glycosylation and could also affect affinity for glucose. The other functional effects of different glycosylation states are not clear although there is evidence suggesting that they are involved in GLUT1 trafficking and substrate affinity.

GLUT 1 expression is controlled by the hypoxia-inducible factor 1 (HIF-1), which is a key regulator in cellular adaptations to a decrease in partial pressure of oxygen [73]. HIF- $1 \alpha$ protein is unstable under normoxic conditions and is constantly degraded by activity of prolyl hydroxylases [74]. During hypoxia, HIF-1 $\alpha$ protein is stabilized by a decrease in activity of prolyl hydroxylases, binds to its binding partner HIF- $1 \beta$, and translocates to the nucleus to bind to hypoxia-responsive cis-elements [75]. Through this mechanism, HIF-1 activates multiple genes involved in angiogenesis and metabolism, including those genes that regulate glucose uptake and utilization [73]. It has been shown that transient brain ischemia causes an increase in HIF-1 "downstream" genes, including GLUT1 expression [76]. However, it is not clear if this signaling pathway plays any role in controlling GLUT1 expression under normoxic conditions. A recent study revealed that in BECs in primary culture, sodium-glucose cotransporter (SGLT) - mediated glucose uptake was induced during ischemia-like conditions in vitro and was also induced during permanent middle cerebral artery occlusion in vivo [77].

Importance of GLUT1 for the brain homeostasis can be observed in a rare genetic disease known as GLUT1 deficiency syndrome [78] that is caused by heterozygous mutations of the GLUT1 gene and is inherited as an autosomal recessive trait [79]. In this condition brain development and function are severely affected, with microcephaly and number of other CNS symptoms/ signs, including developmental delay, intellectual disability, spasticity, ataxia, dysarthria and myoclonus $[80,81]$. Similar findings were observed after heterozygous mutations of the GLUT1 gene in mice (GLUT1 ${ }^{+/-}$mice), a condition that was associated with reduced expression of GLUT1 in BECs. Those animals showed signs similar to GLUT1-deficient patients, including microcephaly, seizures, incoordination, and spasticity [82].

It has been also postulated that GLUT 1 downregulation may be linked to neuronal deficits in Alzheimer disease (AD). Mooradian et al. in 1993 showed that cerebral cortices from AD patients contained less GLUT1 protein than controls [83]. It remains unclear whether 


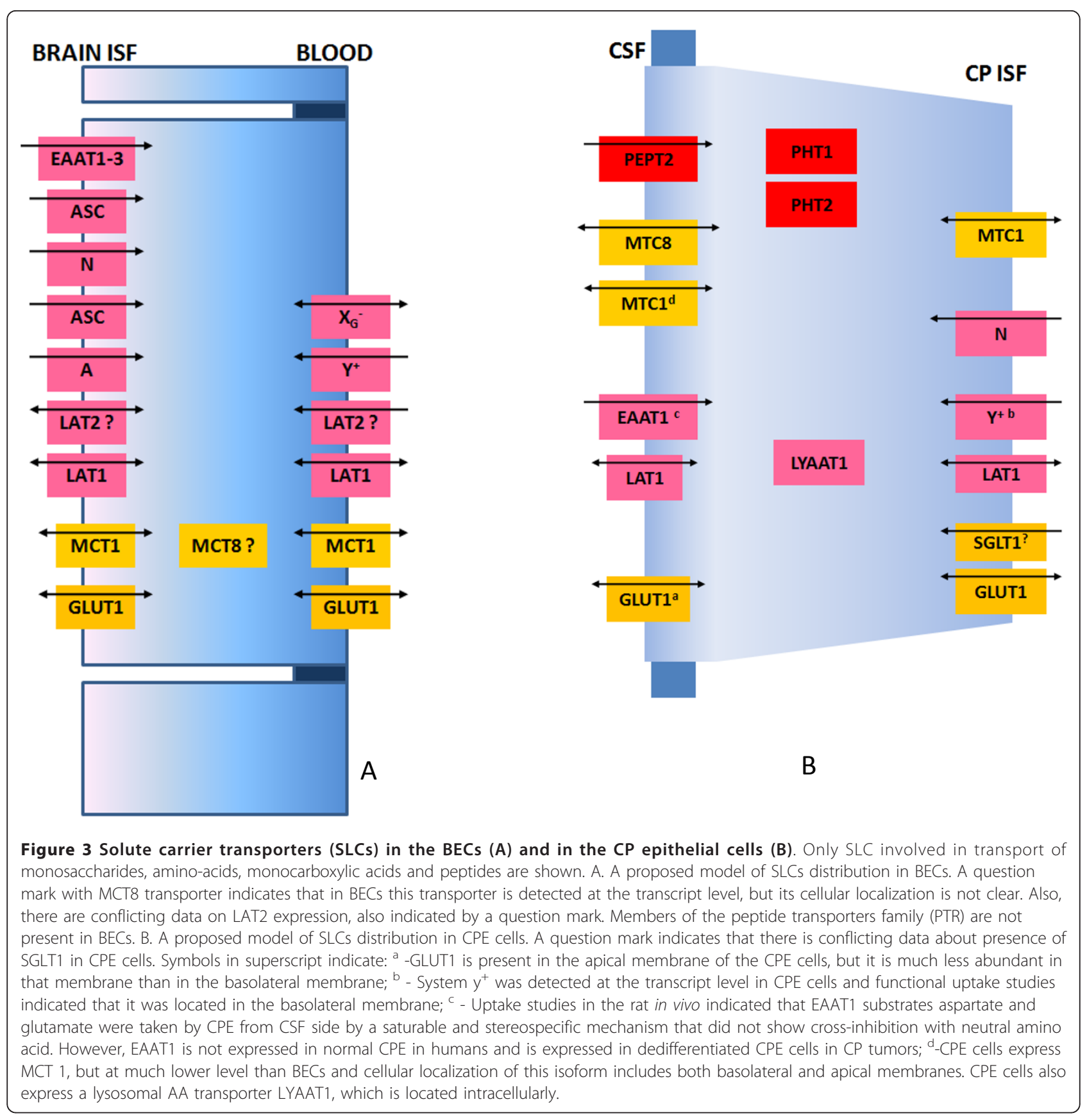

reduced expression of GLUT1 in cortical samples of AD patients was caused by reduced demands of affected tissue or whether reduced glucose availability could be one of the causes for neuronal degeneration. Regional glucose uptake studies have demonstrated that individuals diagnosed with aging-associated cognitive decline had reduced glucose uptake in several cortical regions [84]. Mosconi et al. [85] suggested that reductions of glucose uptake by the hippocampus can predict cognitive decline associated to $\mathrm{AD}$ before clinical diagnosis.
However, given the kinetic properties of GLUT1 [70], even if GLUT1 expression is reduced at the BBB, it should be associated with sufficient downhill transport of glucose to provide enough fuel to support neuronal activity.

It appears that GLUT1 expression at the BBB is also influenced by astrocytes and other glial cells, so that when the brain needs more glucose, GLUT1 expression in the BECs becomes upregulated. Regina et al. [86] found that treatment with conditioned medium obtained from 
glucose-deprived astrocytes increased endothelial GLUT1 expression and glucose uptake in rat BECs; however, no change in GLUT1 expression was observed in endothelial cells treated with astrocyte-conditioned medium when astrocytes were maintained under normoxic conditions. This indicates that hypoxic astrocytes release humoral factors that upregulate GLUT1 expression in BECs. Further insight into a proposed mechanism was provided by Yeh et al. [87] who found that conditioned medium from rat C6 glioma cells under hypoxia up-regulated glucose GLUT1 expression in rat BECs, whereas conditioned medium from C6 cells under normoxia caused no significant effect. This effect is likely to be mediated by VEGF, which is also a HIF-1 "downstream" gene [73]; when C6 cells were transfected with VEGF small interfering RNA that diminishes VEGF mRNA expression, it was found that conditioned medium from transfected cells under hypoxia no longer up-regulated GLUT1 expression in BECs and that a similar effect was observed when VEGF-neutralizing antibody was added to the hypoxic conditioned medium [87]. Interestingly, rat BECs in primary culture often express GLUT3, a transporter that is present in neurons but not in brain capillaries in vivo [86], which may be a sign of dedifferentiation of BECs in culture.

Glucose in the CSF is about $50-60 \%$ of plasma glucose, which creates a downhill gradient towards the CSF. It has been shown that there was a net glucose transfer from the fluid in CP capillaries to the CSF during in situ perfusion of sheep $\mathrm{CP}$ and that this process was $\mathrm{Na}^{+}$-independent [88].

Immunocytochemical studies revealed diffuse GLUT1 immunoreactivity in rats, mice and rabbits $[89,90]$ with the basolateral CPE membrane being stained more intensively (Figure 3B). Other studies could not confirm that GLUT3 [91] and GLUT2 (SLC2A2) [92] were present in the CP epithelium. An immunogold electron microscopy study has revealed very dense staining for GLUT1 in CP capillaries, while staining of CPE was less intense [93]. Interestingly, this study found that while the basolateral membrane showed staining for GLUT1, it was almost absent on the apical membrane [93], indicating low expression. The high affinity hexokinase 1 is abundant in the CPE [91], which may indicate that glucose taken up by GLUT1 is used largely to satisfy the high metabolic demands of the CPE. Reports of expression of the sodium-dependent glucose transporter 1 (SGLT1) are conflicting in the CPE (Figure 3B).

In conclusion, there is a difference between the functional roles of glucose transporters in the BECs and in the CPE; the former provides transcellular flux of glucose towards brain ISF, which is vital for providing the brain with its main fuel; the latter appears to be more important for supplying glucose to support the CPE metabolic demands.

\section{Amino acid transporters}

Brain requires several essential amino acids (AA) for protein synthesis; although the rate-limiting step in brain uptake of circulating amino acids is BBB transport [94], under normal physiologic conditions the synthesis of brain proteins is not rate-limited by the availability of amino acids [95]. It was revealed that the influx of amino acids from blood-to-brain approximates the rates of amino acid incorporation into brain proteins [94].

Most essential AAs are neutral, with long or bulky chains and are substrates for some of the system-L amino acid transporters (LAT) [96]. It is believed that LAT1 (SLC7A5) is the main AA transporter at the BBB; immunohistochemical analyses have shown that the LAT1 was expressed in the BECs in rats in the luminal and abluminal membranes (Figure 3A). It has been shown that, in fact, LAT1 activity is induced in Xenopus oocytes by cloned cDNA from mouse encoding 4F2 light chain (4F2lc), but its trafficking and insertion into the cell membrane depended largely on co-expression with 4F2 heavy chain (4F2hc) as 4F2lc-4F2hc covalent complex (which was also known as CD98 membrane antigen) [97]. This underlines the importance of 4F2 heavy chain in bringing and inserting LAT1/4F2lc into the plasma membrane. Human and rat 4F2hc when inserted into membranes alone induce so-called $y+L-$ like activity (sodium-independent transport for basic amino acids, and sodium-dependent transport for neutral amino acids). In contrast, transient transfection of rat 4F2hc in Chinese hamster ovary cells results in an increase in L-isoleucine transport with characteristics of system L $[98,99]$. Thus, it appears that $4 \mathrm{~F} 2 \mathrm{hc}$ is essential for proper function of LAT1, but this protein itself mediates amino-acid transport. In mouse BECs $4 \mathrm{~F} 2 \mathrm{hc}$ mRNA was the most abundant among all AA transporters mRNAs, as revealed by qPCR [98].

However, RT-PCR data and kinetic analysis of $\left[{ }^{3} \mathrm{H}\right]-$ leucine uptake, revealed that LAT2 (SLC7A6), which has a lower affinity for this substrate, is also expressed in rat BECs in culture [100]. Kinetic analysis of amino acid transport by the brain provided data that could indicate that both LAT1 and LAT2 show affinity for small neutral AAs, alanine, serine and cysteine [101]. However, it should be noted that mouse BECs in primary cultures had significantly downregulated all mRNAs encoding AA transporters, as revealed by qPCR [47]. Some essential amino acid are cationic; these are transported from blood into brain by a $\mathrm{Na}^{+}$-dependent saturable carrier, system $\mathrm{y}^{+}$(SLC7A1) that is present at the luminal side of the BBB (Figure 3A) and expression of $\mathrm{y}^{+}$in BECs exceeds 38 -fold expression in the whole brain homogenate [102].

Beside LAT1, several other AA transporters are present at the abluminal, brain ISF-facing side of the BECs 
(Figure 3A). System A (SLC38A2) (alanine preferring) was first characterized and previous kinetic studies showed that it actively transported small nonessential neutral amino acids [103]. At least four other $\mathrm{Na}$ ${ }^{+}$-dependent carriers exist at the abluminal membrane: system ASC (SLC1A5) alanine, serine, and cysteine preferring, [104], system $\mathrm{Bo}^{+}$(SLC7A3) for basic AAs [105], system N (SLC38A5) for nitrogen rich AA (glutamine, asparagine, and histidine) [106], and excitatory amino acid transporters (EAAT) (SLC1A1-3), that mediate transport of aspartate and glutamate [107]. Small AAs, alanine and serine are transported by two $\mathrm{Na}^{+}$-dependent transport systems that are located exclusively in the abluminal membrane [105]: the system $\mathrm{A}$, which is probably the main route for $\mathrm{Na}^{+}$-dependent alanine transport with a $\mathrm{Km}$ of $0.6 \mathrm{mM}$ and system ASC that also shows affinity for large neutral AA. The physiological importance of those two transport systems is unclear, but they may be related to AA efflux from the brain.

The sodium-dependent system EAAT deserves attention because it permits a net removal of glutamate from the brain. Glutamate concentration in blood is 50-100 $\mu \mathrm{M}[107,108]$; in whole brain homogenate it exceeds 10 $\mathrm{mM}$, while in the brain ISF it is normally kept below 2 $\mu \mathrm{M}$ [109]. Glutamate can exert neurotoxicity if it accumulates in the brain ISF, because, through its action on metabotropic NMDA receptors, it could lead to $\mathrm{Ca}^{++}$ overload, causing neuronal injury or death [110]. Glutamate is released during neurotransmission but is normally rapidly taken up by neurons and neighboring astrocytes. However, during cerebral ischemia and/or hypoxia, this AA accumulates in the brain ISF, especially in regions that are rich in glutaminergic neurons. There are three EAATs present at the abluminal side of the BECs, EAAT1 (SLC1A1), EAAT2 (SLC1A2), and EAAT3 (SLC1A3) [107,110] (Figure 3A) and their action appears to be important to prevent excitotoxicity because they actively remove glutamate from the ISF into the BEC cytoplasm. At the luminal side of the BBB, glutamate is transported by facilitative glutamate transporter $\mathrm{X}_{\mathrm{G}}{ }^{-}$[110]. It has been demonstrated that scavenging glutamate in the blood with a glutamate-scavenging agent oxalocaetate increased the efflux of excess glutamate from the brain and reduced brain damage after closed head injury [111].

Available data on amino acid concentrations in the CSF is inconsistent, but it is clear that CSF to plasma ratios are lower than 1 , ranging from $<0.1$ for neurotransmitters, like glycine and glutamic acid, to $>0.1$ for small neutral AAs [112]. Early functional studies revealed that many neutral AA as well as glutamate and aspartate were taken across the luminal side of the CPE by a $\mathrm{Na}^{+}$-independent mechanism [113]. It was revealed later that the CPE expresses LAT1 [114], which could be responsible for the observed $\mathrm{Na}^{+}$-independent AA uptake, but expression of this transporter is less abundant than expression in the BECs (Figure 3B). A second AA transporter that is abundant in the BECs, the $\mathrm{y}^{+} \mathrm{AA}$ transporter, was also found to be present in the CPE at the transcript level; however, its abundance in the $\mathrm{CP}$ was less than in the BECs [102]. Previous functional uptake studies revealed that arginine and leucine were taken up by the blood side of the sheep CP by a separate transport process that did not show any cross-inhibition with neutral amino acids [115]. Uptake studies have indicated that CPE expresses system $\mathrm{N}$, while the transport activity for small neutral AA (mediated by systems A and ASC) was absent [116] (Figure 3B), which confirms finding by Preston and Segal [115] that uptake of A and ASC substrates by isolated perfused CP was very low. Both choroid plexus epithelium and ependymal cells lining the ventricles express the lysosomal amino acid transporter(LYAAT-1) that mediates $\mathrm{H}^{+}$cotransport with a stoichiometry of $1 \mathrm{H}^{+} / 1$ amino acid [117] (Figure 3B); however its role is not very clear. LYAAT-1 plays a role in the active efflux of amino acids from lysosomes and in the CNS it is also abundantly present in neurons [117].

It has been shown, using ventriculo-cisternal perfusion in rat, that accumulation of aspartate and glutamate by the choroid plexus from CSF side was saturable, stereospecific, not inhibited by neutral amino acid analogues, and shared by both aspartate and glutamate [118]. A recent study in humans revealed that $\mathrm{CPE}$, contrary to the $\mathrm{BBB}$, does not express EAATs [119], which suggests that it does not normally play an active role in removing those excitatory neurotransmitters from brain extracellular fluid. However, de-differentiated CP cells, seen in CP tumors, express EAAT1; this feature distinguishes neoplastic from normal CP and could be used as a helpful diagnostic tool [119].

\section{Monocarboxylate transporters}

As noted above, the CNS is an obligate glucose consumer that depends almost entirely on the supply of glucose from the systemic circulation. However, several findings suggest that glial cells and neurons do not use glucose as a fuel to the same extent: astrocytes take up glucose that is transported across the BECs and use it for the glycolysis, producing lactate that is released into the ISF and subsequently taken up by surrounding neurons [120]. Also, evidences suggest that neurons during development use lactate as an important source of energy during neuronal migration, since in vivo blockade of lactate transport in the brain over postnatal day 1-3 in mice induced a cytoarchitectonic disorganization in the parietal cortex that was likely due to a 
disturbance of cortical neuronal migration and an increased neuronal cell death [121]. Lactic acid has a pKa of 3.9, thus it exists almost entirely as the lactate anion at physiological $\mathrm{pH}$. Both the proton and the lactate or other monocarboxylate anions require a specific transport mechanism to cross cell membranes, which is provided by proton-linked monocarboxylate transporters (MCTs) [122]. Fourteen MCTs have been identified so far [123]. Four MCTs are present in the brain: MCT1, MCT2, MCT4 and MTC8, which are selectively present in distinct cell types and membrane domains [124]. MCT4 is expressed in astrocytes and its main role is to export lactate produced during glycolysis into the ISF; from there lactate is transported into neurons by MCT2 [124]. BECs express MCT1 (SLC16A1) at both luminal and abluminal membranes and also in intracellular organelles (Figure 3A) [125] and this transporter has a fairly high affinity for lactate when compared to other MCTs (Km $3.5 \mathrm{mM}$, [124]). MCT8 (SLC16A2) mRNA and protein are also expressed in cerebral microvessels [126]. Human MTC8 transporter mediates transport of thyroid hormones and the importance of transport for thyroid hormone signaling was revealed by the discovery that inactivating mutations in the human monocarboxylate transporter-8 (MCT8) cause Allan-Herndon-Dudley syndrome, an X-linked developmental disorder characterized by hypotonia, spasticity, muscle weakness, neurological problems, and cognitive impairment due to thyroid hormone deficiency in the CNS [127]. In humans, plasma lactate is below $1 \mathrm{mM}$ under normal physiologic conditions while in the brain ISF it is above $3 \mathrm{mM}$ [64]. Under those conditions the MCT1 at the $\mathrm{BBB}$ probably pays a role in lactate removal from the brain ISF to the blood, to avoid its accumulation in the brain. However, during starvation, when following a ketogenic diet or under hypoxic conditions, plasma lactate and ketone bodies increase so the gradient across the BBB could change. It has been shown that dietinduced ketosis in rats caused a substantial upregulation of MCT1 at the BBB, associated with an increased extraction of plasma ketone bodies by the brain [128]. Interestingly, the rat $\mathrm{BBB}$ transcriptome study has revealed that a tag that identified MCT7 (Slc family 16 member 6) was the second most abundant tag in the microvessel SAGE catalog, with abundance that was only slightly below that of GLUT1 [39].

CPE primarily expresses MTC8, which is located on the apical surface and it is believed to be involved in thyroid hormone transport [126] (Figure 3B). It also expresses MTC1, but at much lower level than BECs and cellular localization of this isoform includes both basolateral and apical membranes [129], while MTC2 transcripts were not found in the CPE [130].

\section{Peptide transporters and receptors}

The delivery of peptides to the brain has important physiological and clinical implications, because in many neurodegenerative diseases it has been found that the application of various growth factors/neuroactive peptides may protect neurons and/or stimulate neuronal growth and repair and, thus, improve outcome for neurological disease. Peptide-based amyloid- $\beta$ (A $\beta$ )-aggregation inhibitors have been shown to decrease the deposition of $A \beta$ in transgenic mouse models of Alzheimer's disease [131]. Also, nerve growth factor (NGF) showed the ability to reduce neuronal degeneration in animal models of Alzheimer's disease [132]. In vitro and in vivo data suggest that treatment with neurotrophic factors such as NGF, glial cell line-derived neurotrophic factor (GDNF), brain-derived neurotrophic factor (BDNF) and several neurotrophins (NTs) could induce survival of specific neuronal populations in Huntington's disease [133]. Treatment strategies aiming to regenerate existing dopaminergic neurons in Parkinson's disease by applying GDNF, BDNF, IGF and NT-4/5 have also been attempted [134,135].

However, blood-to-brain transfer of intact peptides remains controversial. Peptides cannot use AA transport systems for facilitative transport because of the existence of the peptide bond (for a review see [136]). Even dipeptides that contain LNAAs do not show measurable affinity for facilitative transport by LAT1 at the BBB [137]. However, there are specific transport systems that mediate transport of peptides. The peptide transporters that belong to the peptide transporter (PTR) family are solute carrier proteins (SLC15A) responsible for the membrane transport of di- and tripeptides [138]. Another peptide transporter family (PTS), that contain at least 9 members (PTS1-9) mediate transport of larger peptides (more than 3 AAs in chain) and in many tissues act primarily as an efflux pump, removing lipophilic peptides from cellular membranes. PTR family consists of four members, two peptide transporters PEPT1 and 2 (SLC15A1-2) and two histidine transporters that also transport dipeptides (PHT1 and 2, SLC15A3-4). PTRs couple substrate movement across the membranes to movement of protons down an inwardly-directed electrochemical proton gradient [138].

Early studies have shown that arginine vasopressin (AVP) [139], enkephalins [140,141], delta-sleep-inducing peptide (DSIP) [142] and luteinizing-hormone-releasing hormone (LHRH) had a measurable volume of distribution in the guinea pig brain after in situ perfusion but the rates of blood-brain transfer were $10^{3}-10^{4}$ fold lower than rates of carrier-mediated amino-acid transport. Tetrapeptide tyrosine melanocyte-stimulating inhibitory factor 1 (Tyr-MIF-1) was the first peptide shown to pass 
from blood to the brain by a saturable system [143]. Although there is no evidence so far that any of the PTR four members, that could mediate efflux transport of di- and tri-peptides are present in the BECs, these cells probably express at least some PTS members located at the abluminal side that mediate efflux transport of several small peptides from the brain ISF: enkephalins, Tyr-MIF-1, arginine vasopressin (AVP) and LHRH [144]. For example, pituitary adenylate cyclaseactivating polypeptide (PACAP), which has neuroprotective effects against ischemia, can pass across the $\mathrm{BBB}$, but its efflux, which is mediated by PTS-6, severely restricts its net entry into the brain ISF. However, when PTS-6 expression in BECs was inhibited by antisense targeting, brain accumulation of PACAP increased significantly [145], which indicates that the main role of this transporter is efflux transport. Thus, it appears that $\mathrm{BBB}$ transport system for peptides could be involved in impeding blood-to-brain ISF transfer of intact peptides. The brain delivery of peptides is further impeded by the existence of various enzymes in BECs that modify AA side chains or hydrolyze peptide bonds. These enzymes include $\gamma$-glutamyl transpeptidase, aromatic acid decarboxylase, dipeptidyl(amino)peptidase IV, and aminopeptidases A and N [146]. However, it has been shown that some neuropeptides, when present in capillaries, could be transferred to the brain ISF in intact form, like DSIP [147].

Larger peptides and proteins that have receptors present at the luminal side of BECs could use receptormediated transcytosis to pass across the $\mathrm{BBB}$ and that mechanism was revealed for insulin [148], transferrin [149], certain cytokines [150], leptin [151,152], immunoglobulin G [153], and insulin-like growth factor [154]. It seems that $A \beta$ could also pass the BBB by receptormediated transcytosis. This peptide (MW $\sim 4500 \mathrm{Da})$ is bound in plasma to several proteins, including albumin, apolipoprotein E (apoE), apolipoprotein J (apoJ), transthyretin (TTR), $\alpha 2$-macroglobulin $(\alpha 2 \mathrm{M})$ and low-density lipoprotein receptor related protein-1 (LRP1) [155-157]. There is evidence which suggests that influx of $A \beta$ into the brain across the BBB involves binding of this peptide to the receptor for advanced glycation end products (RAGE) and subsequent receptor-mediated transcytosis [158]. Advanced glycation end products (AGE) accumulate in the basement membrane of the $\mathrm{BBB}$ and this triggers increased expression of RAGE in the BECs, which could lead to increased blood-to-brain transcytosis of $A \beta$ [159]. In the brain ISF, $A \beta$ is degraded while some remains bound to apoJ, apoE and $\alpha 2 \mathrm{M}$ [160]. Some reports suggest that expression of LRP1 has an important role in the prevention of $A \beta$ accumulation in the brain by several mechanisms. One mechanism includes binding of brain A $\beta$ to LRP1 at the abluminal (brain ISF-facing) membrane of the BECs in vitro, which leads to a subsequent transcytosis of $A \beta$ LRP1 complex [161]. Some of the A $\beta$-apoJ complexes from the brain ISF bind to LRP2 (also known as megalin), which also triggers transcytosis of this complex and subsequent brain-to-blood efflux of $A \beta$ [162]. $A \beta$ also binds to LRP1 in plasma; taking into account the abundance of LRP1 in plasma when compared to amount of circulating $A \beta$, this binding provides a peripheral 'sink' for plasma $A \beta[160]$. However, a key point in this hypothesis is challenged by in vivo findings of Ito and colleagues [163], who revealed, using the brain efflux index technique in mouse that simultaneous injection of receptor-associated protein (RAP) with radiolabelled $A \beta$ failed to cause inhibition of $A \beta$ efflux transport across the BBB. Since RAP is a chaperon protein which inhibits the ligand interactions with LRP1, the authors conclude that LRP1 interaction with $A \beta$ is not essential for brain efflux of $A \beta$ and that this efflux is LRP1 independent [163]. This finding was challenged [160], by a group who claim that Ito and co-workers have not performed control experiments to determine ${ }^{125} \mathrm{I}-\mathrm{A} \beta$ integrity prior to its use and/or at the end of the experiment in brain extracts.

In adsorptive endocytosis, the interaction of a glycoprotein, or positively-charged peptide, with glycoproteins or negatively-charged regions of the BECs causes adsorption of the molecule to the surface of the BECs. This in turn causes internalization of the molecule into the BEC [164]. However, it is not clear what determines the fate of those vesicles; they could be delivered to the Golgi, or lysosomes, or they could move across the cytoplasm and fuse with the abluminal membrane [165]. An alternative strategy to enhance peptide delivery to the brain is modification of amino acid side chains in small peptides (150-500 Da) to improve liposolubility (ideally a log octanol/water partition coefficient should be 0.5 6.0), to enable these peptides to diffuse across the BEC membrane [166]. Although it has been proposed that peptides with MW $>400 \mathrm{Da}$ cannot cross the $\mathrm{BBB}$ [167], so far there is no clear evidence that an absolute MW cutoff point exists for crossing the BBB. However, this strategy faces another obstacle, because with increasing lipid solubility sequestration by liver and binding to plasma proteins also increases, which decreases the half-life of a peptide in plasma and reduces availability for interaction with BECs. Also, free diffusion is often followed by proteolytic cleavage in the BECs or active efflux from the BECs by P-gp or PTSs [144]. For example, blood-to-brain transport of TyrMIF-1 and the enkephalins is very limited because of the action of PTS1 in the abluminal membrane of BECs, 
which mediates efflux of those peptides [168]. Also, Pgp mediates efflux transport of several opiate peptides and inhibition of efflux pumps was accompanied by a several-fold increase in peptide accumulation by the brain [169].

Another alternative strategy is to use receptormediated transcytosis through the BBB for drug delivery to the brain. This strategy, known as a "Trojan horse", includes conjugation of different peptides that have very limited delivery to the brain to monoclonal antibodies against one of the $\mathrm{BBB}$ peptide receptors, like the transferrin receptor [170]; binding of the antibody to receptor triggers endocytosis, as explained above. However, these receptors are not brain specific and are widely expressed in peripheral organs, a fact that limits their applicability for brain-targeting. A recent study used phage display in an in situ brain perfusion model to screen for peptide ligands that bind specifically to brain endothelium [171]. Using this strategy, new peptide ligands were identified that showed significant binding to human brain endothelium but not to other human endothelial cells, so they may be used for specific targeting of drugs to the blood-brain barrier [171].

BECs are not only involved in transport/transcytosis of peptides/proteins, but also as a target for various bioactive peptides and in synthesis of neuroactive peptides. It has been shown recently in a study on AVP-deficient Brattleboro rats, that BECs produce and secrete several chemokines after brain injury; this production is under the synergistic control of AVP and TNF- $\alpha$ [172]. The AVP effects were mediated by c-Jun $\mathrm{N}$-terminal kinase (JNK), a kinase that has increased activity in BECs in response to injury [172].

Contrary to the situation at the $\mathrm{BBB}$, several lines of evidence indicate that members of the PTR family of proton-coupled peptide transporters are expressed at the BCSFB; this includes PEPT2, which is expressed in the CP membranes [173] and PHT1 [174] (Figure 3B). PEPT2 is a proton-coupled oligopeptide transporter and it is abundant in epithelial layers, including kidney, where it plays an important role in renal reabsorption of di- and tri-peptides $[138,175]$. All evidence available so far suggest that PEPT2 is located in the apical, CSF -facing side, and it was responsible for $95 \%$ of dipeptide (glycylsarcosine - GlySar) uptake by isolated CP that was incubated in artificial CSF containing GlySar [173]. Wild-type mice had greater choroid plexus concentrations of GlySar and a 5-fold greater CP/CSF ratio when compared to PEPT2-null mice [175] and it was located at the apical side of the rat CPE in primary culture [176]. PEPT1 and PEPT2 have wide affinity for di-and tripeptides with more than 8000 different substrates identified so far [138]. Apart from CPE, in the CNS PEPT2 is located in ependymal cells lining cerebral ventricles [177]. Thus, the likely function of this transporter is to clear di- and tri-peptides from the CSF. An intense hybridization signal for PHT1 was found in the brain, especially in the hippocampus and cerebellum, while the signal in the CP was weaker [174]. PEPTs also transport a number of peptidomimetics, so the presence of this transporter at the apical membrane of the CPE could severely restrict entry of blood-borne peptidomimetics into the CSF. The CPE is also involved in receptor-mediated endocytosis of peptides. It has been shown that transport of blood-born leptin to the CSF involves leptin binding to LRP2 (megalin) in the CPE and transcytosis of the LRP2/leptin complex through epithelial cells [178]. The CPE also plays a role in clearance of $A \beta$ from the CSF and it appears that LRP2 is involved in this process, since it has been shown that $A D$ patients have reduced levels of LRP2 at the CP, which may decrease efflux of $A \beta$ from the CSF and could be, therefore, one of the causes of increased brain levels of $A \beta$ [179]. Another receptor belonging to the same LDL receptor gene family appears also to be involved in $A \beta$ clearance from the CSF: LRP1 is normally confined to the CPE cytoplasm where it binds $A \beta$; however, exposure to lead causes protein kinase $\mathrm{C}$-mediated relocation of LRP1 and disrupts normal clearance of $A \beta$ from the CSF, leading to its accumulation in the CPE [180].

The CPs are important not only in clearance of peptides from the CSF and delivery of blood-borne peptides to the CSF, but also as a target for a number of hormones. Atrial natriuretic peptide (ANP) binds to its receptors in the CPE, which generates CGMP; this second messenger alters ion transport, thereby slowing CSF production [181]. The presence of natriuretic peptide receptor (NPR) A and NPR B, both containing a guanylyl-cyclase intracellular domain, was confirmed by immunostaining in CPE, and also in some ependymal cells in adult Sprague-Dawley rats [182]. Rats with congenital hydrocephalus had a lower number of binding sites for radiolabelled ANP in the choroid plexus, as compared to the control rats, indicating that this could be one of the pathophysiological mechanisms underlying excessive CSF production [183]. The CPE is also one of the extra-hypothalamic sources of AVP [184]. The regulation of choroidal AVP synthesis is similar to that observed in the hypothalamus and it has been shown that chronic hypernatremia increases the expression of AVP in the CP [185]. It also appears that a well-known inhibitory effect of centrally-released angiotensin II on CSF production by the CPs is mediated by AVP production in the $\mathrm{CP}$ and its paracrine action on $\mathrm{V} 1$ receptors present in the CPE [186], which involves V1 receptormediated decrease in $\mathrm{Cl}$ - efflux from epithelial cells and consequent reduction in CSF formation [187]. An important role of CP-born bioactive peptides is 
proposed in brain recovery after traumatic brain injury (TBI). It is believed that upregulated growth factors and neurotrophins produced by the CPs and by the ependymal layer are brought by the CSF bulk flow to brain regions close to the ependymal layer and those factors could be important for neural restoration through enhanced neurogenesis and angiogenesis after TBI [188].

An important feature of $\mathrm{CPE}$, that is not present in the BECs, is a synthesis of transthyretin (TTR), which functions as a carrier for thyroxin and retinol-binding protein [189]. It also sequesters A $\beta$ peptide, and TTR levels in the CSF appear to be inversely correlated with Alzheimer's disease (AD) onset and progression. TTR, thyroxin-binding globulin (TBG) and albumin form a "buffering" system for plasma L-thyroxin because of their overlapping affinities for that hormone. CPs have the highest concentration of transthyretin (TTR) mRNA in the body and the percentage of TTR to total protein synthesis in choroid plexus exceeds 10\% [189]. However, absence of TTR in genetically-modified mice did not affect delivery of T4 to the brain [190]. 5 - $\alpha$-dihydrotestosterone treatment increased TTR protein levels in CPE cells in primary culture and induced TTR transcription in these cells via an androgen receptor-independent pathway [191]. On the other hand, treatment with 17ß-estradiol increased expression of TTR in CPs in vivo at both transcript and protein levels via an oestrogen receptor $\alpha$-dependent pathway [192,193]. Also, expression of TTR both in vitro and in vivo was upregulated by treatment with progesterone, which involves a progesterone receptor-mediated mechanism [194]. These findings could at least partially explain mechanisms involved in protective effects of progesterone and estradiol against the onset of $\mathrm{AD}$.

\section{ABC-transporters, organic anion/cation transporters and organic anion transporting polypeptide expression at the $\mathrm{BBB}$ and the BCSFB}

The family of ATP-binding cassette (ABC) transporters is divided into subfamilies: the multidrug-resistance proteins or P-glycoproteins (Abcb subfamily, HUGO names $A B C B 1-11)$, the multidrug resistance-related proteins MRPs (Abcc subfamily, HUGO names ABCC1-5) and the breast cancer-resistance protein (BCRP, HUGO names ABCG1-8) [195]. Their substrates range from small ions to large polypeptides and transport occurs against steep concentration gradients using energy that is provided by ATP-hydrolysis [196]. Transport of amphipathic molecules (i.e. organic anions) is sodiumindependent and mediate by transport proteins that belong to two SCL families, the organic anion/cation transporter family (OATs - SLC22) and the organic anion transporting polypeptides family (OATPs SLC21). Members of the SLC21 family mediate transport of large, amphipathic solutes such as bile salts, thyroid hormones, leukotriene, and various steroids conjugates and xenobiotics [197]. OATs accept smaller and more hydrophilic substrates than those carried by members of the SLC21 family, including neurotransmitter metabolites, cAMP, cGMP, and xenobiotics such as para-aminohippuric acid, $\beta$-lactam and sulfonamide antibiotics, non-steroidal anti-inflammatory drugs, antiviral drugs, antidiuretics, antiepileptics, methotrexate [197]. Substrates for OCTs include neurotransmitters (5-HT, dopamine), choline, tetraethylammonium ion, cimetidine, N1-methylnicotinamide [198].

Given the mechanism of action of particular ABC transporters, the precise localization of these proteins at the BBB and BCSFB is essential for understanding their role in physiology and in drug delivery to the brain. For example, a luminally-located P-glycoprotein, which is quantitatively the most important $\mathrm{ABC}$ transporter at the $\mathrm{BBB}$, would mediate efflux transport of its substrates from the luminal membrane back to blood, which would impede influx of substrates to the brain. On the other hand, abluminally located P-gp would mediate transport of substrates from the abluminal membrane into the brain ISF, thereby facilitating influx of substrates to the brain. In brain capillaries, P-gp is predominantly and abundantly expressed in the luminal membrane [199] and it mediates efflux of substrates back into the blood after they initially diffuse into the endothelial cell membrane (Figure 4A). By this action, $\mathrm{P}$-gp restricts penetration of its substrates into the brain. A report has suggested that endothelial P-gp is expressed at the nuclear membrane of rat brain microvessel endothelial cell line RBE4 [200]. In rodents, two multidrug resistance proteins are encoded by the genes Mdr1a and Mdr1b and only Mdr1a is found in endothelial cells [201]. Studies using P-gp knockout mice have mainly contributed to the view of P-gp as the main gatekeeper at the BBB [202]. Both SAGE analysis of the rat $\mathrm{BBB}$ transcriptome and $\mathrm{qPCR}$ analysis of mouse $\mathrm{BBB}$ transcriptome revealed that P-gp mRNA was highly expressed in brain microvasculature [39,47]. The expression of MRPs is less clear and there are many conflicting reports: some authors suggested that BECs express multidrug resistance-associated protein Mrp1 (for the review see [203]) at the luminal side, while others revealed by immunofluorescence staining that this protein is scarce at the $\mathrm{BBB}$ and localized abluminally [199] (Figure 4A). However, MRP4, MRP5 and probably MRP2 are located on the luminal membrane of BECs (for reviews see [203,204]); MRP3 has only been detected in capillaries from brain tumors [205]. Breast cancer-resistance protein (BCRP, ABCG2) is expressed at the luminal membrane of human BECs [206] (Figure $4 \mathrm{~A}$ ) and its substrate specificity partially overlaps 


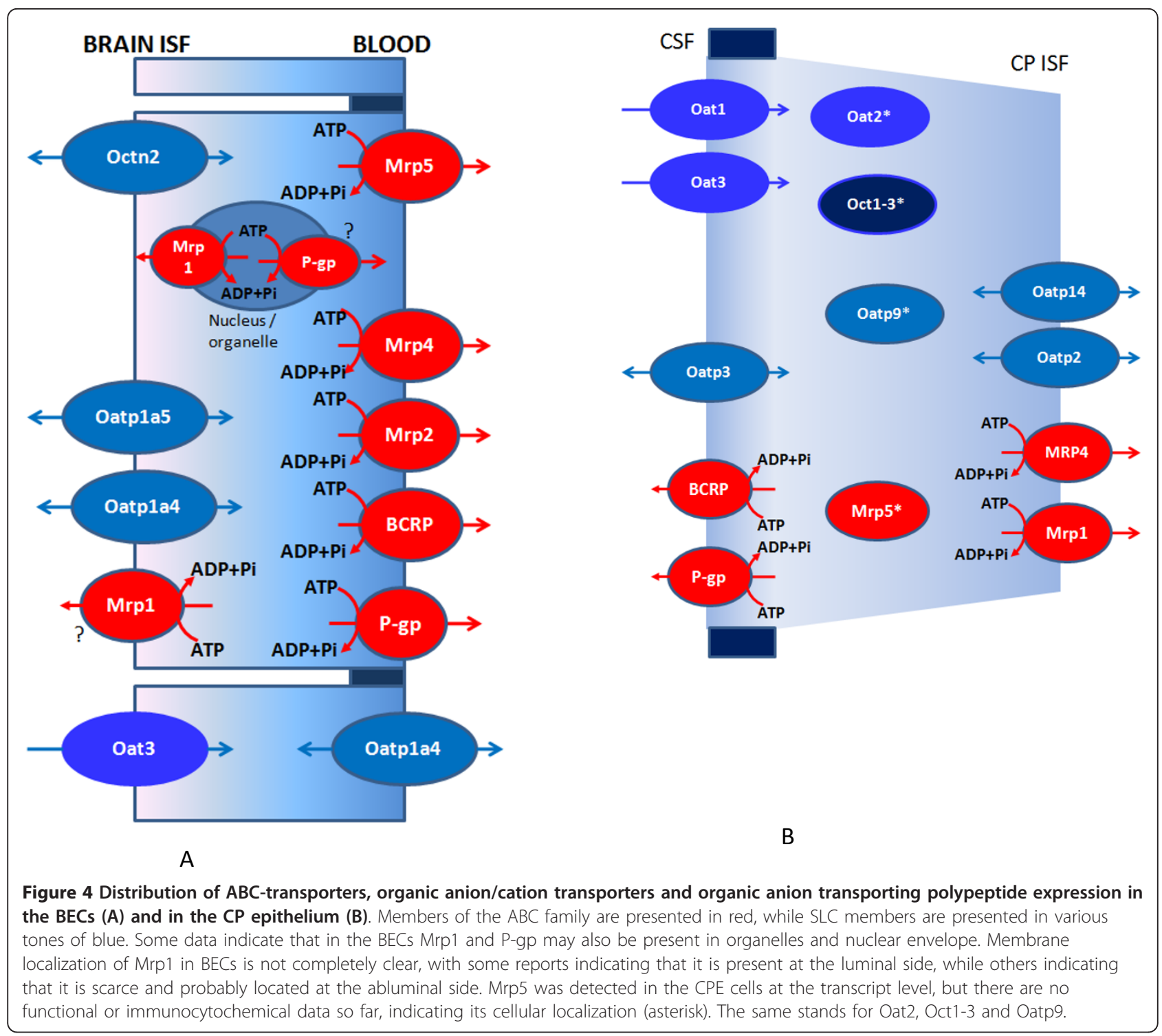

with that of P-gp. Data suggest that after P-gp, BCRP is the second most abundant $\mathrm{ABC}$ transporter expressed in human BECs [207]. In rodents, Oatp1a4 (Slc21a5, old protein name Oatp2), Oatp1a5 (Slc21a7, old protein name Oatp3) and Oatp1c1 (Slc21a14, old protein name Oatp14) are expressed at blood-brain interfaces with Oatp1a5 being located primarily abluminally and Oatp1a4 on luminal and abluminal membranes $[126,203,208]$. In humans OATP1A2 (SLC21A3, old protein name OATP-A) and OATP2B1 (SLC21A9, old protein name OATP-B) are localized at the luminal membrane of BECs [209]. At the rodent BBB, Oat3 (Slc22a8) is predominantly localized at the abluminal membrane [210], while OAT3 (SLC22A8) and OAT1 (SLC22A6) are found in epithelial cells of the human CP [211], but their precise localization is not clear. Electrogenic organic cation transporters (OCTs) are expressed in rodent and human neurons and glial cells and not in BECs in humans [212]. The proton gradientdriven OCTN2 (SLC22A5), which mediates transport of carnitine, is expressed in the abluminal membrane in bovine BECs [213].

Many of those transporters have also been identified in the CPs at the transcript or protein level or by functional transport studies [214]. P-gp expression in the human and rodent $\mathrm{CP}$ has been detected $[215,216]$, but other research groups have found P-gp in the CP to be scarce or undetectable $[217,218]$. Studies that detected it in the CP reported that P-gp was located at the apical (CSF-facing) side and in sub-apical cell compartments [216] (Figure 4B), which means that P-gp transports substrates back into the CSF. So, the direction of P-gpmediated transport at the BCSFB appears to be opposite to that at the BBB. The most abundant efflux 
transporter in the $\mathrm{CP}$ is $\mathrm{Mrp} 1$ ( $\mathrm{ABCC} 1)$ and it is located basolaterally [216] (Figure 4B); MRP4 is also present in the basolateral membrane of the human CPE cells [218]. Presence of mRNA for Mrp5 (ABCC5) in the CP has also been revealed [219]. BCRP is located on the CSF side of CPE cells in mice [220]. Cellular localization of two Oatps in CP has been confirmed by immunochemical studies: Oatp1a4, (Slc21a5, old protein name Oatp2) is located at the basolateral membrane, while Oatp1a5 (Slc21a7, old protein name Oatp3) is located on the apical membrane [221,222], with Oatp2 being probably the most abundant Oapt in the CP [223]. Oatp2b1 (Slc21a9, old protein name Oatp9) and Oatp1c1 (Slc21a14, old protein name Oatp14) were detected in $\mathrm{CP}$ at the transcript and protein level; precise cellular localization of Oatp9 is unknown [224], while Oatp14 appears to be located primarily at the basolateral membrane (Figure $4 \mathrm{~B}$ ), and is involved in thyroid hormone transport [126]. Members of the Slc22a gene family, OAT1 (SLC22a6) and OAT3 (SLC22a8) are located at the apical side of the CPE [225], while expression of OAT2 mRNA in the CP was confirmed but there are no data about cellular localization [224]. The presence of Octs 1-3 has been confirmed by RT-PCR but there are no further data on their cellular localization.

Overall, the two important differences between the $\mathrm{BBB}$ and the BCSFB with regard to expression of these transporters are: $\mathrm{P}$-gp is present at the blood-facing side in the BECs and it is the most abundant transporter at the $\mathrm{BBB}$, while in the $\mathrm{CP} \mathrm{P}$-gp is expressed predominantly on the apical, CSF-facing side of the CPE cells and it appears that the P-gp function in the $\mathrm{CP}$ is not that critical for brain homeostasis, since the amount of that protein in the CP is negligible ( 0.5\%) when compared to its amount in BECs [217]. On the other hand, at the BBB Mrp1 is fairly sparse while in CPE it is probably the most abundant transporter, exceeding by at least 200-fold that in the BECs [217].

Since P-gp appears to be the main gatekeeper at the $\mathrm{BBB}$, a very important observation was that xenobiotics, environmental toxins and pollutants, mediators of inflammation and even the neurotransmitter glutamate could affect expression of P-gp in the BECs, thereby reducing or increasing drug delivery to the brain [213]. Briefly, exposure of rat BECs to xenobiotics or pollutants that are ligands to androstane receptor (CAR) or to pregnane-X receptor (PXR) causes activation of these two receptors and then activated CAR/PXR translocate to the nucleus to increase $\mathrm{P}$-gp gene expression $[226,227]$. A practical consequence of this mechanism is that treatment with drugs that are P-gp substrates could reduce delivery of other $\mathrm{P}$-gp substrates to the brain. Inflammatory signals have more complex effects on Pgp expression: initially they cause a loss in P-gp activity that is followed by delayed increase in activity and expression [228]. Rapid and reversible loss of P-gp transport function is not accompanied by change in protein expression and it involves binding of ligands (endothelin - ET and tumor necrosis factor alpha TNF $\alpha$ ) to toll-like receptor-4 (TLR4) or TNF- $\alpha$ receptor 1 (TNF-R1), which is followed by activation of nitric oxide synthase (NOS) and protein kinase $\mathrm{C}$ (PKC). NOS and PKC modify activity of the existing P-gp. Delayed induction of $\mathrm{P}$-gp expression includes signaling via TNF- $\alpha$ [229] and ET-1, but in this case a signaling cascade activates nuclear factor- $\kappa \mathrm{B}$ (NF-kB), which is a ubiquitous transcription factor that controls the expression of genes; NF-kB then translocates to nucleus affecting gene expression [230]. TNF- $\alpha$-mediated signaling includes not only an increase in expression of P-gp, but also reduces the amount of Mrp2 and Mrp4 proteins [229]. Also, it was revealed that diesel exhaust particles (DEP) that can be found in polluted air could increase expression of P-gp, Mrp1, Mrp2 and BCRP in BECs [231]. The proposed mechanism involves TNF- $\alpha$ signaling, which means that chronic exposure to DEPs could cause additional oxidative and inflammatory stress for the brain; this corresponds to finding that DEPs induce inflammatory responses in microglia [232].

Another challenging area for $\mathrm{ABC}$ transporter research is a hypothesis that their failure could be associated with Alzheimer's disease (AD) where P-gp and Bcrp could serve as efflux pumps for $\beta$-amyloid peptide $[233,234]$. The existing reports are conflicting: it has been revealed that brain capillaries of Alzheimer's patients have reduced expression of P-gp [235] and increased expression of BCRP [234]; however, a recent study by confocal microscopy that quantified peak fluorescence values of cross-sectional profiles of brain microvessels, revealed expression of $\mathrm{P}$-gp protein to be significantly lower in hippocampal vessels of patients with $\mathrm{AD}$ compared to normal individuals, whereas that of MRP4 or BCRP protein was not changed [236]. However, the same study reported that analysis of the sections at protein level via Western blotting or at transcript level by qPCR did not reveal significantly lower expression for either P-gp or BCRP [236].

\section{Ion transporters in the BBB and CP}

There is evidence suggesting that there is a bulk flow of the brain ISF from brain capillaries towards the ventricular space and that ISF merges with the CSF; this flow takes place predominantly along perivascular spaces (for a review see [237]). This indicates that there is a constant production of a "new" ISF in the brain which contributes to total volume of the CSF. Although some of the ISF is probably generated from water produced by brain metabolism, fluid secretion by BECs appears to be 
an important source of this ISF [237], accounting for at least $30 \%$ of the ISF production [238]. This process is essential for maintaining correct fluid balance in the brain. Two membrane proteins that work simultaneously but at different membranes of the BECs are key regulators of net sodium and chloride transport across the BBB: $\mathrm{Na}^{+}, \mathrm{K}^{+}$-ATPases (ATP1 family) and the $\mathrm{Na}^{+}$, $\mathrm{K}^{+}, 2 \mathrm{Cl}^{-}$cotransporter (SLC12 family). The $\mathrm{Na}^{+}, \mathrm{K}$ ${ }^{+}$-ATPase is localized on the abluminal membrane and provides a driving force for the net ion and water movement across the BBB [239] (Figure 5A); 3 alpha(ATP1A1-3) and 2 beta- (ATP1B1-2) subunit isoforms were found in rat BECs, which means that six structurally distinct $\mathrm{Na}^{+}, \mathrm{K}^{+}$-ATPase isoenzymes are likely to be expressed in brain microvessels [240]. As in other tissues, the activity of this enzyme is tightly associated with cell volume regulation [241]. The $\mathrm{Na}^{+}-\mathrm{K}^{+}-2 \mathrm{Cl}^{-}$cotransporter is located at the luminal side of BECs
[242] and its activity is regulated by PKC signalling [243]. In addition, rat brain endothelial cells express Kv1 and Kir2 potassium channels; these are probably located on both the luminal and abluminal sides of the BECs [244] (Figure 5A). Furthermore, BECs also express two ion exchangers that belong to the SLC family and are probably involved in intracellular $\mathrm{pH}$ regulation: chloride-bicarbonate $\left(\mathrm{Cl}^{-}, \mathrm{HCO}_{3}{ }^{-}\right.$) exchanger (SLC4A1) and sodium-hydrogen $\left(\mathrm{Na}^{+}, \mathrm{H}^{+}\right.$-) exchanger (SLC4A6). Both isoforms of $\mathrm{Na}^{+}, \mathrm{H}^{+}$-exchanger (Nhe1 and Nhe2) are expressed on the luminal membrane, whereas chloridebicarbonate exchanger(Ae1) is expressed at both luminal and abluminal membranes of the BECs (Figure 5A) [245]. Net flux of $\mathrm{K}^{+}$at the BBB is critical for brain homeostasis, since changes in concentration affect resting membrane potential; however, net flux of this ion across the $\mathrm{BBB}$ is not well understood. Both $\mathrm{Na}^{+}, \mathrm{K}$ ${ }^{+}$-ATPase and the $\mathrm{Na}^{+}-\mathrm{K}^{+}-2 \mathrm{Cl}^{-}$cotransporter bring this

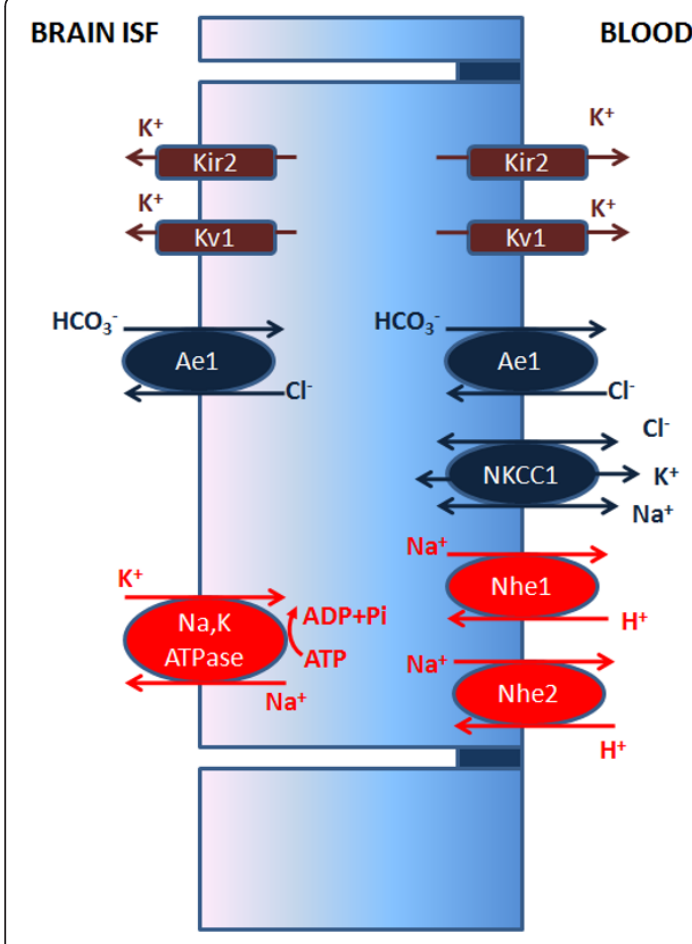

A

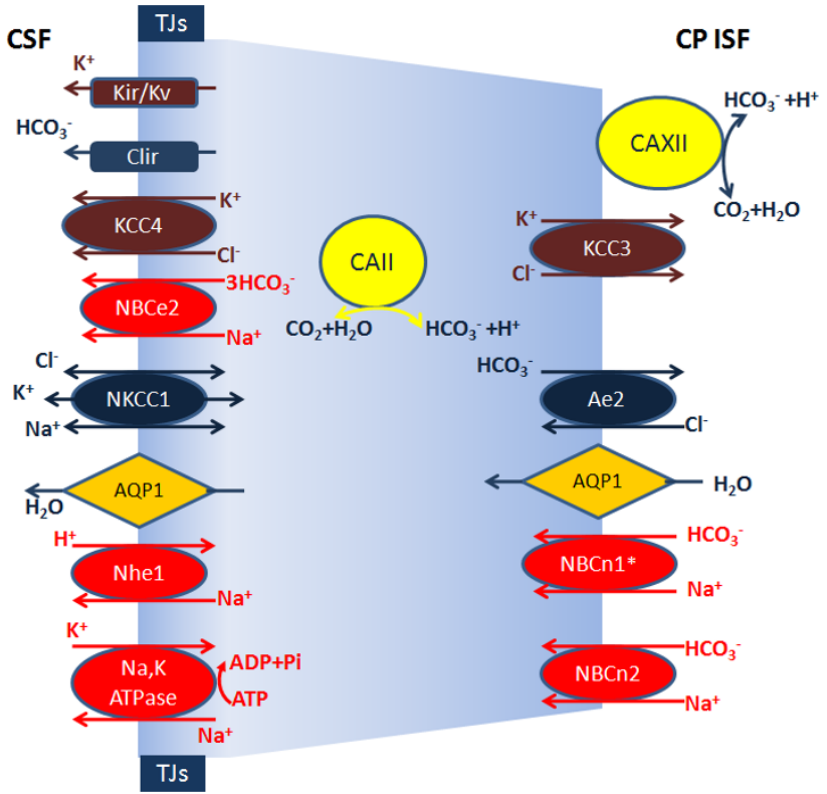

B

Figure 5 Distribution of ion transporters and channels in the BECs (A) and in the CP epithelium (B). Only those transporters and channels that play a role in vectorial transport of $\mathrm{Na}^{+}, \mathrm{Cl}^{-}, \mathrm{HCO}_{3}{ }^{-}$and $\mathrm{K}^{+}$are shown. These include $\mathrm{Na}^{+}, \mathrm{K}^{+}-\mathrm{ATPase}$, potassium channels $\mathrm{Kir}$ and $\mathrm{Kv}$, chloride/bicarbonate channel Clir and members of the SLC: $\mathrm{Na}^{+}, \mathrm{HCO}_{3}{ }^{-}$cotransporters 1 and 2 ( $\mathrm{NBCn} 1$ and 2$), \mathrm{Cl}^{-}, \mathrm{HCO}_{3}{ }^{-}$exchangers 1 and $2(\mathrm{Ae}$ 1 (in the $\mathrm{BBB}$, figure $\mathrm{A}$ ) and $\mathrm{Ae} 2$ (in the $\mathrm{CP}$, figure $\mathrm{B}$ ), $\mathrm{Na}^{+}, \mathrm{H}^{+}$exchanger 1 and 2 (Nhe1 and Nhe2), $\mathrm{K}^{+}$- $\mathrm{Cl}^{-}$cotransporters 3 and 4 ( $\mathrm{KCC} 3$ and 4 , in the $\mathrm{CP}$, figure $\mathrm{B}), \mathrm{Na}^{+}-\mathrm{K}^{+}-2 \mathrm{Cl}$ - cotransporter 1 (NKCC1, in the $\mathrm{BBB}$, figure $\mathrm{A}$ ) and electrogenic $\mathrm{Na}^{+}, \mathrm{HCO}_{3}{ }^{-}$exchanger (NBCe2, in the $\mathrm{CP}$, figure $\left.\mathrm{B}\right)$. In addition, localization of two carbonic anhydrase isoenzymes in the CP epithelium (figure B), CA2 and CA12 are shown, as well as localization of aquaporin 1 (AQP1). Symbol * indicates that NBCn1 was detected in CPE, but it probably does not play a role in vectorial transport of these two ions. 
ion into the BECs and at least two potassium channels exist on both sides (Figure 5A). A hypothesis suggested that there was a net $\mathrm{K}^{+}$efflux across the $\mathrm{BBB}$, which contributed to low $\mathrm{K}^{+}$concentration in the brain ISF [246]. However, the CSF recovered from the brain, contains 2.5-3.0 $\mathrm{mM} \mathrm{K}^{+}$and the CSF originates either from $\mathrm{CP}$ secretion or from the brain ISF, although the relative contribution of those two sources is a matter of debate. Thus, at least one of these two (CSF secreted by the CPS or brain ISF secreted by the BECs) have to be a source of $\mathrm{K}^{+}$in the CSF. CPs in fact mainly reabsorb $\mathrm{K}^{+}$ from the CSF (see below). Thus, bearing in mind conservation of mass, a speculation could also be made that $\mathrm{K}^{+}$found in the CSF is, at least partially, $\mathrm{K}^{+}$that was secreted at the BBB.

Ion transport at the $\mathrm{BBB}$ also plays an important role in regulation of endothelial cell $\mathrm{pH}$, especially bicarbonate transport driven by $\mathrm{Cl}^{-}, \mathrm{HCO}_{3}{ }^{-}$-exchanger and $\mathrm{H}^{+}$transport driven by $\mathrm{Na}^{+}, \mathrm{H}^{+}$-exchanger. It has been shown that following in vitro loading of BECs with small acid load, $\mathrm{HCO}_{3}{ }^{-}$influx was mainly responsible for the acid extrusion and it was mediated partially by $\mathrm{Cl}^{-}$dependent $\mathrm{HCO}_{3}{ }^{-}$transporters. However, after large acid loads, BECs removed acid almost solely by $\mathrm{Na}^{+}, \mathrm{H}^{+}$exchange, with the rate of its activity depending linearly on intracellular $\mathrm{pH}$ [247]. Following an alkaline load to BECs, the intracellular $\mathrm{pH}$ was restored by acid loading which occurred via $\mathrm{Cl}^{-} / \mathrm{HCO}_{3}{ }^{-}$exchange [247].

Ion transporters in the CPs have been studied intensively because ion transport across the CPE drives CSF secretion, which could be considered as the most apparent and the most important function of CPs. CSF has a number of important roles in brain homeostasis, including reduction of the effective weight of the brain by being submerged in CSF, removal of waste products of metabolism, removing excess neurotransmitters and debris from the surface lining epithelium and delivering signalling molecules (for a review of CSF functions see [248]). Bicarbonate transport by the CPE directly affects the $\mathrm{pH}$ of CSF, which in turn affects neuronal activity in the respiratory centre in the medulla oblongata.

Overall, two main processes are driven by ion transporters in the CP. First, the transepithelial basolateral-toCSF movement of sodium, bicarbonate and chloride creates a small osmotic force driving net movement of water in the same direction. Water movement across the CPE is via aquaporin 1, the waater channel which is abundantly expressed in the apical membrane and less so in the basolateral membrane (Figure 5B). This water channel is typical for epithelia that have a high rate of water transfer generated by a small osmotic gradient. Second, CSF to basolateral movement of potassium takes place $[249,250]$. However, it should be remembered that there are net fluxes of other ions across the $\mathrm{CPE}: \mathrm{Ca}^{2+}$, organic anions and cations.

Although it would be possible for $\mathrm{Na}^{+}$to diffuse through paracellular spaces in the CPE (taking into account that TJs in the $\mathrm{CP}$ epithelium are relatively "leaky" due to the expression of certain claudins), analysis of electrochemical relations between the plasma and the CSF reveals that a gradient created by a CSF lumenpositive transepithelial voltage, which impedes $\mathrm{Na}^{+}$diffusion towards the CSF, exceeds the blood-to-ventricle chemical gradient for $\mathrm{Na}^{+}$; thus, the net movement of $\mathrm{Na}^{+}$from the blood side to the ventricle has to be an active ATP-dependent process [250]. Ion transporters expressed on the basolateral side of the $\mathrm{CP}$ epithelium load cells with $\mathrm{Na}^{+}$, while ion transporters expressed at the apical (CSF) side transport $\mathrm{Na}^{+}$from cells into the CSF. Two major anions, $\mathrm{Cl}^{-}$and $\mathrm{HCO}_{3}{ }^{-}$also pass the CPE layer via a transcellular route; the CSF concentrations of both $\mathrm{Cl}^{-}$and $\mathrm{HCO}_{3}{ }^{-}$are less than predicted for simple diffusion, which suggests that the paracellular route contributes negligibly to the overall transfer.

It is believed that the main entry route for $\mathrm{Na}^{+}$at the basolateral membrane is a stilbene-sensitive $\mathrm{Na}^{+}$$\mathrm{HCO}_{3}{ }^{-}$transporter (SLC4A10 or NBCn2/NBCE) (Figure 5B). This transporter was also known as $\mathrm{Na}^{+}$- dependent $\mathrm{Cl}^{-} / \mathrm{HCO}_{3}{ }^{-}$exchanger, but the reported dependence of this transporter on intracellular $\mathrm{Cl}$ - has been disputed and the transporter was characterized as an electroneutral $\mathrm{Na}^{+}-\mathrm{HCO}_{3}{ }^{-}$cotransporter [251]. In the $\mathrm{CP}$, this transporter is expressed only in the basolateral membrane and transports $\mathrm{Na}^{+}$and $\mathrm{HCO}_{3}{ }^{-}$into the cell [251]. Mice that had this transporter genetically removed had severe reduction in brain ventricle size, which suggested that the rate of CSF secretion was decreased [252]. This transporter is also important for loading CPE cells with $\mathrm{HCO}_{3}{ }^{-}$. The $\mathrm{Na}^{+}, \mathrm{HCO}_{3}$ - cotransporter 1 (SLC4A7 or NBCn1) is also expressed in the CPE basolateral membrane [251] (Figure 5B), but evidence suggests that it does not play a major role in basolateral $\mathrm{Na}^{+}$loading and vectorial flux of this ion [250]. $\mathrm{Cl}^{-}$accumulates in the $\mathrm{CPE}$ by action of the $\mathrm{Cl}^{-}, \mathrm{HCO}_{3}{ }^{-}$-exchanger (anion exchange protein 2, SLC4A2 or Ae2) [253]. In the CPE, $\mathrm{Cl}^{-}$movement intracellularly is driven by an outwardlydirected transmembrane gradient for $\mathrm{HCO}_{3}{ }^{-}$that is created by the basolateral $\mathrm{Na}^{+}, \mathrm{HCO}_{3}{ }^{-}$-cotransport [250].

Transport of these ions through the apical membrane to the CSF involves several proteins. $\mathrm{Na}^{+}, \mathrm{K}^{+}$- ATPase, which in the CPE is located exclusively in the apical membrane, is probably the most important $\mathrm{Na}^{+}$extruder [253] (Figure 5B). Three $\mathrm{Na}^{+}, \mathrm{K}^{+}$-ATPase subunits are expressed in $\mathrm{CP}$ epithelium at the transcript level: $\alpha 1$ (ATP1A1), $\beta 1$ (ATP1B1) and $\beta 2$ (ATP1B2) [240]. The $\mathrm{Na}^{+}, \mathrm{H}^{+}$-exchanger 1 (SLC9A1 or Nhe1) has also a 
predominantly apical localization in the CPE [212]; however, it is involved in intracellular $\mathrm{pH}$ regulation rather than in extrusion of $\mathrm{Na}^{+}$and it has been shown that $\mathrm{Na}$ ${ }^{+}, \mathrm{H}^{+}$-exchanger 1 knockout mouse lacked $\mathrm{Na}^{+}$-dependent intracellular $\mathrm{pH}$ recovery following acidification of CPE cells [254].

Transport of $\mathrm{Cl}^{-}$across apical side is driven by a gradient towards the CSF and takes place mainly via $\mathrm{K}^{+}-\mathrm{Cl}^{-}$ -cotransporter 4 (SLC12A7 or KCC4), that is expressed on the apical side (Figure 5B). The apical side also expresses the $\mathrm{Na}^{+}-\mathrm{K}^{+}-2 \mathrm{Cl}^{-}$- cotransporter 1 (SLC12A2 or NKCC1) [255], but its contribution to overall ion flux in this tissue is controversial because the net driving force for this transporter is close to zero due to high intracellular $\mathrm{Na}^{+}$and $\mathrm{Cl}$ - and low $\mathrm{K}^{+}$in the CSF [255], A recent report suggested that this transporter does not contribute to net ion fluxes [256]. Bicarbonate transport to the CSF across the apical surface is mediated mainly by the electrogenic $\mathrm{Na}^{+}, \mathrm{HCO}_{3}{ }^{-}$-exchanger (SLC4A5 or $\mathrm{NBCe} 2 / \mathrm{NBC} 4)$ that couples transport of $1 \mathrm{Na}^{+}$with 3 $\mathrm{HCO}_{3}{ }^{-}$and has an important role in CSF pH regulation [244]. In amphibian $\mathrm{CP} \mathrm{HCO}_{3}{ }^{-}$flux across the apical membrane is mainly via $\mathrm{Cl}^{-}$ion channel that has high permeability for $\mathrm{HCO}_{3}{ }^{-}$[6]. This channel (Clir) plays some role in apical $\mathrm{HCO}_{3}^{-}$extrusion in mammals, but permeability of this channel for $\mathrm{HCO}_{3}{ }^{-}$appears to be small.

It should be stressed that this section has focused only on molecular biology of transport for the principal ions: $\mathrm{Na}^{+}, \mathrm{K}^{+}, \mathrm{Cl}^{-}$and $\mathrm{HCO}_{3}{ }^{-}$and that it has not covered the transport of polyvalent ions such as $\mathrm{Ca}^{++}, \mathrm{Mg}^{++}, \mathrm{PO}_{4}{ }^{3-}$ and $\mathrm{Fe}^{++}$.

\section{Conclusion}

Studies of the past two decades have provided insight into the molecular biology which underlines function of the two most important blood-brain fluid interfaces, the $\mathrm{BBB}$ and the BCSFB. Efficient homeostatic mechanisms established by those two barriers control composition of brain extracellular fluids, the ISF and CSF. These are vital to normal neuronal function and signal processing in the CNS. Two obvious functions that are common to the BBB and the BCSFB are the restriction of free diffusion and the transport of nutrients, waste products, signalling molecules and ions between blood and brain extracellular fluids. However, those two structures show important differences in their respective roles that are underlined by differences in expression of cell junction proteins, transport proteins and ion channels. An important similarity between the two barriers is that they are both dynamic systems and are able to respond rapidly to changes in brain requirements. The molecular basis of this feature is that the BBB and the BCSFB could be regulated via a number of molecular mechanisms under normal physiological or pathological conditions. Further insights into molecular mechanisms involved in $\mathrm{BBB}$ and $\mathrm{BCSFB}$ regulation should provide molecular cues for targeting the brain barriers in CNS diseases.

\section{List of abbreviations}

a 2M: a2-macroglobulin; AA: amino acid; AD: Alzheimer's disease; AJ: adherens junctions; ANP: atrial natriuretic peptide; AVP: arginine vasopressin; BCRP: breast cancer resistance protein; BCSFB: blood-cerebrospinal fluid barrier; BDNF: brain-derived neurotrophic factor; BEC: brain endothelial cells; CAR: androstene receptor; CBF: cerebral blood flow; CP: choroid plexus; CPE: choroid plexus epithelium; CSF cerebrospinal fluid; DEP: diesel exhaust particles; DSIP: delta-sleep inducing peptide; EAAT: excitatory amino acid transporter; GDNF: glial cell line-derived neurotrophic factor; HIF-1: hypoxiainducible factor 1; HUGO: Human Genome Organization; ISF: interstitial fluid; JAM: junctional adhesion molecules; JNK c-Jun N-terminal kinase; LAT: system-L amino acid transporter; LRP1: low-density lipoprotein receptor related protein-1; MCT: monocarboxylate transporter; MRP: multidrug resistance-related protein; NFKB: nuclear factor-KB; NGF: nerve growth factor; OAT: organic anion transporter; OATP: organic anion transporting polypeptide; P-gp: P-glycoprotein; PKC: protein kinase C; PTR: peptide transporters; PXR: pregnane-X receptor; qPCR- real time PCR; RAGE: receptor for advanced glycation end products; RAP: receptor-associated protein; SLC: solute carriers; TBI: traumatic brain injury; TEER: transendothelial/ transepithelial electrical resistance; TGF: transforming growth factor; TJ: tight junction; TTR: transthyretin; VEGF: vascular endothelial growth factor; ZO: zonulla occludens;

\section{Acknowledgements and Funding}

I acknowledge help of my colleagues Dr James Donald Craik, Department of Biochemistry, and Dr Slava Malatiali, Department of Physiology, for their efforts in improving manuscript style and clarity.

\section{Authors' contributions}

ZR: sole author. The author has read and approved the final version of the manuscript.

\section{Competing interests}

The authors declare that they have no competing interests.

Received: 31 October 2010 Accepted: 18 January 2011

Published: 18 January 2011

\section{References}

1. Crone C, Christensen O: Electrical resistance of a capillary endothelium. J Gen Physiol 1981, 77:349-371.

2. Bradbury MW: The Concept of a Blood-Brain Barrier Chichester: Wiley; 1979.

3. Begley DJ, Brightman MW: Structural and functional aspects of the bloodbrain barrier. Prog Drug Res 2003, 61:39-78.

4. Kuschinsky W, Paulson OB: Capillary circulation in the brain. CerebrovasC Brain Metab Rev 1992, 4:261-286.

5. Del Bigio MR: The ependyma: a protective barrier between brain and cerebrospinal fluid. Glia 1995, 14:1-13.

6. Saito Y, Wright EM: Regulation of bicarbonate transport across the brush border membrane of the bull-frog choroid plexus. J Physiol 1984, 350:327-342.

7. Welch $\mathrm{K}$, Araki H: Features of the choroid plexus of the cat, studied in vitro. In Fluid Environment of the Brain. Edited by: Cserr HF, Fenstermacher JD, Fend V. New York: Academic Press; 1975:157-165.

8. Scott DE, Kozlowski GP, Sheridan MN: Scanning electron microscopy in the ultrastructural analysis of the mammalian cerebral ventricular system. Int Rev Cytol 1974, 37:349-388.

9. Keep RF, Jones HC: A morphometric study on the development of the lateral ventricle choroid plexus, choroid plexus capillaries and ventricular ependyma in the rat. Dev Brain Res 1990, 56:47-53.

10. Hawkins BT, Davis TP: The blood-brain barrier neurovascular unit in health and disease. Pharmacol Rev 2005, 57:173-185

11. Martin-Padura I, Lostaglio S, Schneemann M, Williams L, Romano M, Fruscella P, Panzeri C, Stoppacciaro A, Ruco L, Villa A, Simmons D, Dejana E: 
Junctional adhesion molecule, a novel member of the immunoglobulin superfamily that distributes at intercellular junctions and modulates monocyte transmigration. J Cell Biol 1998, 142:117-127.

12. Gonzalez-Mariscal L, Betanzos A, Nava P, Jaramillo BE: Tight junction proteins. Prog Biophys Mol Biol 2003, 81:1-44.

13. Li Y, Fanning AS, Anderson JM, Lavie A: Structure of the conserved cytoplasmic C-terminal domain of occludin: identification of the ZO-1 binding surface. J Mol Biol 2005, 352:151-164.

14. Feldman GJ, Mullin JM, Ryan MP: Occludin: structure, function and regulation. Adv Drug Deliv Rev 2005, 57:883-917.

15. Andreeva AY, Piontek J, Blasig IE, Utepbergenov DI: Assembly of tight junction is regulated by the antagonism of conventional and novel protein kinase C isoforms. Int J Biochem Cell Biol 2006, 38:222-233.

16. Saitou M, Furuse M, Sasaki H, Schulzke D, Fromm M, Takano H, Noda T, Tsukita S: Complex phenotype of mice lacking occludin, a component of tight junction strands. Mol Biol Cell 2000, 11:4131-4142.

17. Saitou M, Fujimoto K, Doi Y, Itoh M, Fujimoto T, Furuse M, Takano H, Noda T, Tsukita S: Occludin-deficient embryonic stem cells can differentiate into polarized epithelial cells bearing tight junctions. J Cell Biol 1998, 141:397-408.

18. Bamforth SD, Kniesel U, Wolburg H, Engelhardt B, Risau W: A dominant mutant of occludin disrupts tight junction structure and function. J Cell Sci 1999, 112:1879-1888.

19. Terai T, Nishimura N, Kanda I, Yasui N, Sasaki T: JRAB/MICAL-L2 is a junctional Rab13-binding protein mediating the endocytic recycling of occludin. Mol Biol Cell 2006, 17:2465-2475.

20. Romanitan MO, Popescu BO, Winblad B, Bajenaru OA, Bogdanovic N: Occludin is overexpressed in Alzheimer's disease and vascular dementia. J Cell Mol Med 2007, 11:569-579.

21. Heiskala M, Peterson PA, Yang Y: The roles of claudin superfamily proteins in paracellular transport. Traffic 2001, 2:93-98.

22. Piontek J, Winkler L, Wolburg H, Muller SL, Zuleger N, Piehl C, Wiesner B, Krause G, Blasig IE: Formation of tight junction: determinants of homophilic interaction between classic claudins. FASEB J 2008, 22:146-158.

23. Nitta T, Hata M, Gotoh S, Seo Y, Sasaki H, Hashimoto N, Furuse M, Tsukita S Size-selective loosening of the blood-brain barrier in claudin-5-deficient mice. J Cell Biol 2003, 161:653-660.

24. Ruffer C, Gerke V: The C-terminal cytoplasmic tail of claudins 1 and 5 but not its PDZ-binding motif is required for apical localization at epithelial and endothelial tight junctions. Eur J Cell Biol 2004, 83:135-144.

25. Matter K, Balda MS: Holey barrier: claudins and the regulation of brain endothelial permeability. J Cell Biol 2003, 161:459-460.

26. Van Itallie CM, Anderson JM: The role of claudins in determining paracellular charge selectivity. Proc Am Thorac Soc 2004, 1:38-41.

27. Wolburg H, Wolburg-Buchholz K, Liebner S, Engelhardt B: Claudin- 1, claudin-2 and claudin-11 are present in tight junctions of choroid plexus epithelium of the mouse. Neurosci Lett 2001, 307:77-80.

28. Wolburg H, Noell S, Wolburg-Buchholz K, Mack AF, Fallier-Becker P: Agrin, aquaporin-4, and astrocyte polarity as an important feature of the blood-brain barrier. Neuroscientist 2009, 15:180-193.

29. Goldmann EE: Vitalfarbung am Zentralnervensystem. Abh preuss Akad Wiss Phys-Math 1913, 1:1-60.

30. Wolburg H, Paulus W: Choroid plexus: biology and pathology. Acta Neuropathol 2010, 119:75-88.

31. Sandri C, Akert K, Bennett MV: Junctional complexes and variations in gap junctions between spinal cord ependymal cells of a teleost Sternarchus albifrons (Gymnotoidei). Brain Res 1978, 143:27-41.

32. Zamora AJ, Thiesson D: Tight junctions in the ependyma of the spinal cord of the urodele Pleurodeles waltlii. Anat Embryol 1980, 160:263-274.

33. Mollgard K, Balslev Y, Lauritzen B, Saunders NR: Cell junctions and membrane specializations in the ventricular zone (germinal matrix) of the developing sheep brain: a CSF-brain barrier. J Neurocytol 1987, 16:433-444.

34. Bazzoni G, Dejana E: Endothelial cell-to-cell junctions: molecular organization and role in vascular homeostasis. Physiol Rev 2004 84:869-901.

35. Bazzoni G, Martinez-Estrada OM, Mueller F, Nelboeck P, Schmid G, Bartfai T, Dejana $\mathrm{E}$, Brockhaus M: Homophilic interaction of junctional adhesion molecule. J Biol Chem 2000, 275:30970-30976.
36. Itoh M, Sasaki H, Furuse M, Ozaki H, Kita T, Tsukita S: Junctional adhesion molecule (JAM) binds to PAR-3: a possible mechanism for the recruitment of PAR-3 to tight junctions. J Cell Biol 2001, 154:491-497.

37. Suzuki A, Ishiyama C, Hashiba K, Shimizu M, Ebnet K, Ohno S: aPKC kinase activity is required for the asymmetric differentiation of the premature junctional complex during epithelial cell polarization. J Cell Sci 2002, 115:3565-3573.

38. Huber JD, Egleton RD, Davis TP: Molecular physiology and pathophysiology of tight junctions in the blood-brain barrier. Trends Neurosci 2001, 24:719-725.

39. Enerson BE, Drewes LR: The rat blood-brain barrier transcriptome. J Cereb Blood Flow Metab 2006, 26:959-973.

40. Koto T, Takubo K, Ishida S, Shinoda H, Inoue M, Tsubota K, Okada Y, Ikeda E: Hypoxia disrupts the barrier function of neural blood vessels through changes in the expression of claudin-5 in endothelial cells. Am J Pathol 2007, 170:1389-1397.

41. Kago T, Takagi N, Date I, Takenaga Y, Takagi K, Takeo S: Cerebral ischemia enhances tyrosine phosphorylation of occludin in brain capillaries. Biochem Biophys Res Commun 2006, 339:1197-1203.

42. Mark KS, Davis TP: Cerebral microvascular changes in permeability and tight junctions induced by hypoxia-reoxygenation. Am J Physiol Heart Circ Physiol 2002, 282:H1485 H1494.

43. Fischer S, Wiesnet M, Marti HH, Renz D, Schaper W. 2004: Simultaneous activation of several second messengers in hypoxia-induced hyperpermeability of brain derived endothelial cells. J Cell Physiol 2004, 198:359-369.

44. Ronaldson PT, Demarco KM, Sanchez-Covarrubias L, Solinsky CM, Davis TP: Transforming growth factor-beta signaling alters substrate permeability and tight junction protein expression at the blood-brain barrier during inflammatory pain. J Cereb Blood Flow Metab 2009, 29:1084-98.

45. Lochhead JJ, McCaffrey G, Quigley CE, Finch J, DeMarco KM, Nametz N, Davis TP: Oxidative stress increases blood-brain barrier permeability and induces alterations in occludin during hypoxia-reoxygenation. I Cereb Blood Flow Metab 2010, 30:1625-1636.

46. Willis $\mathrm{CL}$, Meske DS, Davis TP: Protein kinase $\mathrm{C}$ activation modulates reversible increase in cortical blood-brain barrier permeability and tight junction protein expression during hypoxia and posthypoxic reoxygenation. J Cereb Blood Flow Metab 2010, 30:1847-1859.

47. Lyck R, Ruderisch N, Moll AG, Steiner O, Cohen CD, Engelhardt B, Makrides V, Verrey F: Culture-induced changes in blood-brain barrier transcriptome: implications for amino-acid transporters in vivo. J Cereb Blood Flow Metab 2009, 29:1491-1502.

48. Vestweber D: VE-cadherin: the major endothelial adhesion molecule controlling cellular junctions and blood vessel formation. Arterioscler Thromb Vasc Biol 2008, 28:223-232.

49. Meng W, Takeichi M: Adherens junction: molecular architecture and regulation. Cold Spring Harb Perspect Biol 2009, 1:a002899.

50. Williams MJ, Lowrie MB, Bennett JP, Firth JA, Clark P: Cadherin-10 is a novel blood-brain barrier adhesion molecule in human and mouse. Brain Res 2005, 1058:62-72.

51. Lampugnani MG, Dejana E: Adherens junctions in endothelial cells regulate vessel maintenance and angiogenesis. Thromb Res 2007, 120:S1-S6.

52. Lippoldt A, Jansson A, Kniesel U, Andbjer B, Andersson A, Wolburg H, Fuxe $\mathrm{K}$, Haller $\mathrm{H}$ : Phorbol ester induced changes in tight and adherens junctions in the choroid plexus epithelium and in the ependyma. Brain Res 2000, 854:197-206.

53. Dean M, Hamon Y, Chimini G: The human ATP-binding cassette (ABC) transporter superfamily. J Lipid Res 2001, 42:1007-1017.

54. Dwyer DS, Vannucci SJ, Simpson IA: Expression, regulation, and functional role of glucose transporters (GLUTs) in brain. Int Rev Neurobiol 2002, 51:159-88.

55. Hawkins RA, O'Kane RL, Simpson IA, Vina JR: Structure of the blood-brain barrier and its role in the transport of amino acids. J Nutr 2006, 136:218S-226S

56. Kido Y, Tamai I, Okamoto M, Suzuki F, Tsuji A: Functional clarification of MCT1-mediated transport of monocarboxylic acids at the blood-brain barrier using in vitro cultured cells and in vivo BUI studies. Pharm Res 2000, 17:55-62.

57. Spector $R$, Johanson CE: Vitamin transport and homeostasis in mammalian brain: focus on Vitamins B and E. J Neurochem 2007, 103:425-438 
58. Isakovic AJ, Abbott NJ, Redzic ZB: Brain to blood efflux transport of adenosine: blood-brain barrier studies in the rat. J Neurochem 2004 90:272-86.

59. Redzic ZB, Biringer J, Barnes K, Baldwin SA, Al-Sarraf H, Nicola PA, Young JD, Cass CE, Barrand MA, Hladky SB: Polarized distribution of nucleoside transporters in rat brain endothelial and choroid plexus epithelial cells. $J$ Neurochem 2005, 94:1420-1426.

60. Isakovic AJ, Dencic SM, Segal MB, Redzic ZB: Transport of $\left[{ }^{14} \mathrm{C}\right]$ hypoxanthine by sheep choroid plexus epithelium as a monolayer in primary culture: $\mathrm{Na}^{+}$-dependent and $\mathrm{Na}^{+}$-independent uptake by the apical membrane and rapid intracellular metabolic conversion to nucleotides. Neurosci Lett 2008, 431:135-140.

61. Redzic ZB, Malatiali SA, Craik JD, Rakic ML, Isakovic AJ: Blood-brain barrier efflux transport of pyrimidine nucleosides and nucleobases in the rat. Neurochem Res 2009, 34:566-573.

62. Simpson IA, Carruthers A, Vannucci SJ: Supply and demand in cerebral energy metabolism: the role of nutrient transporters. J Cereb Blood Flow Metab 2007, 27:1766-1791.

63. Tsacopoulos M, Magistretti PJ: Metabolic coupling between glia and neurons. J Neurosci 1996, 16:877-885.

64. Abi-Saab WM, Maggs DG, Jones T, Jacob R, Srihari V, Thompson J, Kerr D, Leone P, Krystal JH, Spencer DD, During MJ, Sherwin RS: Striking differences in glucose and lactate levels between brain extracellular fluid and plasma in conscious human subjects: effects of hyperglycemia and hypoglycemia. J Cereb Blood Flow Metab 2002, 22:271-9.

65. Mueckler M, Caruso C, Baldwin SA, Panico M, Blench I, Morris HR, Allard WJ, Lienhard GE, Lodish HF: Sequence and structure of human glucose transporter. Science 1985, 229:941-945.

66. Kayano T, Fukumoto H, Eddy RL, Fan YS, Byers MG, Shows TB, Bell Gl: Evidence for a family of human glucose transporter-like proteins. Sequence and gene localization of a protein expressed in fetal skeletal muscle and other tissues. J Biol Chem 1988, 263:15245-15248.

67. Doege H, Schürmann A, Bahrenberg G, Brauers A, Joost HG: Glucose transporter 8 (GLUT8): a novel sugar facilitator with glucose transport activity. J Biol Chem 2000, 275:16275-16280.

68. Olson AL, Pessin JE: Structure, function, and regulation of the mammalian facilitative glucose transporter gene family. Annu Rev Nutr 1996, 16:235-256.

69. Nishimura H, Pallardo FV, Seidner GA, Vannucci S, Simpson IA, Birnbaum MJ: Kinetics of GLUT1 and GLUT4 glucose transporters expressed in Xenopus oocytes. J Biol Chem 1993, 268:8514-8520.

70. Duarte JM, Morgenthaler FD, Lei H, Poitry-Yamate C, Gruetter R: Steadystate brain glucose transport kinetics re-evaluated with a four-state conformational model. Front Neuroenergetics 2009, 1:6.

71. Maher F, Vannucci SJ, Simpson IA: Glucose transporter proteins in brain. FASEB J 1994, 8:1003-1010.

72. Kumagai AK, Dwyer KJ, Pardridge WM: Differential glycosylation of the GLUT1 glucose transporter in brain capillaries and choroid plexus. Biochim Biophys Acta 1994, 1193:24-30.

73. Semenza GL: Oxygen-dependent regulation of mitochondrial respiration by hypoxia-inducible factor 1. Biochem J 2007, 405:1-9.

74. Semenza GL: HIF-1: mediator of physiological and pathophysiological responses to hypoxia. J Appl Physiol 2000, 88:1474-1480.

75. Bruick RK, McKnight SL: A conserved family of prolyl-4-hydroxylases that modify HIF. Science 2001, 294:1337-1340.

76. Chavez JC, LaManna JC: Activation of hypoxia-inducible factor-1 in the rat cerebral cortex after transient global ischemia: potential role of insulin-like growth factor-1. J Neurosci 1993, 22:8922-8931.

77. Vemula S, Roder KE, Yang T, Bhat GJ, Thekkumkara TJ, Abbruscato TJ: A functional role for sodium-dependent glucose transport across the blood-brain barrier during oxygen glucose deprivation. J Pharmacol Exp Ther 2009, 328:487-495.

78. Guo X, Geng M, Du G: Glucose transporter 1, distribution in the brain and in neural disorders: its relationship with transport of neuroactive drugs through the blood-brain barrier. Biochem Genet 2005, 43:175-87.

79. Rotstein M, Engelstad K, Yang H, Wang D, Levy B, Chung WK, De Vivo DC: Glut1 deficiency: Inheritance pattern determined by haploinsufficiency. Ann Neurol 2010.

80. Klepper J, Leiendecker B: GLUT1 deficiency syndrome-2007 update. Dev Med Child Neurol 2007, 49:707-16.
81. Brockmann K: The expanding phenotype of GLUT1-deficiency syndrome. Brain Dev 2009, 31:545-552.

82. Wang D, Pascual JM, Yang H, Engelstad K, Mao X, Cheng J, Yoo J, Noebels JL, De Vivo DC: A mouse model for Glut-1 haploinsufficiency. Hum Mol Genet 1993, 15:1169-1179.

83. Mooradian AD, Chung HC, Shah GN: GLUT-1 expression in the cerebra of patients with Alzheimer's disease. Neurobiol Aging 1993, 18:469-474.

84. Hunt A, Schonknecht P, Henze M, Seidl U, Haberkorn U, Schroder J: Reduced cerebral glucose metabolism in patients at risk for Alzheimer's disease. Psychiatry Res 155:147-154.

85. Mosconi L, De Santi S, Li J, Tsui WH, Li Y, Boppana M, Laska E, Rusinek H, de Leon MJ: Hippocampal hypometabolism predicts cognitive decline from normal aging. Neurobiol Aging 2008, 29:676-692.

86. Régina A, Morchoisne S, Borson ND, McCall AL, Drewes LR, Roux F: Factor (s) released by glucose-deprived astrocytes enhance glucose transporter expression and activity in rat brain endothelial cells. Biochim Biophys Acta 2001, 1540:233-242.

87. Yeh WL, Lin CJ, Fu WM: Enhancement of glucose transporter expression of brain endothelial cells by vascular endothelial growth factor derived from glioma exposed to hypoxia. Mol Pharmacol 2008, 73:170-177.

88. Deane R, Segal MB: The transport of sugars across the perfused choroid plexus of the sheep. J Physiol 1985, 362:245-260.

89. Gerhart DZ, LeVasseur RJ, Broderius MA, Drewes LR: Glucose transporter localization in brain using light and electron immunocytochemistry. J Neurosci Res 1989, 22:464-472.

90. Harik SI, Kalaria RN, Andersson L, Lundahl P, Perry G: Immunocytochemical localization of the erythroid glucose transporter: abundance in tissues with barrier functions. J Neurosci 1990, 10:3862-3872.

91. Fields HM, Rinaman L, Devaskar SU: Distribution of glucose transporter isoform-3 and hexokinase I in the postnatal murine brain. Brain Res 1999, 846:260-264.

92. Arluison M, Quignon M, Nguyen P, Thorens B, Leloup C, Penicaud L: Distribution and anatomical localization of the glucose transporter 2 (GLUT2) in the adult rat brain-an immunohistochemical study. J Chem Neuroanat 2004, 28:117-36.

93. Cornford EM, Hyman S, Cornford ME, Damian RT: Glut1 glucose transporter in the primate choroid plexus endothelium. J Neuropathol Exp Neurol 1998, 57:404-414.

94. Pardridge WM: Brain metabolism: a perspective from the blood-brain barrier. Physiol Rev 1983, 63:1481-1535.

95. Wurtman RJ, Moskowitz MA, Munro HN: Transsynaptic control of neuronal protein synthesis. In The Neurosciences: Fourth Study Program. Edited by: Schmitt FO, Norden FG. Cambridge: MIT Press; 1979:897-909.

96. Verrey F: System L: heteromeric exchangers of large, neutral amino acids involved in directional transport. Pflugers Arch 2003, 445:529-533.

97. Nakamura E, Sato M, Yang H, Miyagawa F, Harasaki M, Tomita K, Matsuoka S, Noma A, Iwai K, Minato N: 4F2 (CD98) heavy chain is associated covalently with an amino acid transporter and controls intracellular trafficking and membrane topology of 4F2 heterodimer. J Biol Chem 1999, 274:3009-3016.

98. Estévez R, Camps M, Rojas AM, Testar X, Devés R, Hediger MA, Zorzano A, Palacín M: The amino acid transport system $\mathrm{y}+\mathrm{L} / 4 \mathrm{~F} 2 \mathrm{hc}$ is a heteromultimeric complex. FASEB J 1998, 12:1319-1329.

99. Bröer S, Bröer A, Hamprecht B: Expression of the surface antigen 4F2hc affects system-L-like neutral-amino-acid-transport activity in mammalian cells. Biochem J 1997, 324:535-541.

100. Kido Y, Tamai I, Uchino H, Suzuki F, Sai Y, Tsuji A: Molecular and functional identification of large neutral amino acid transporters LAT1 and LAT2 and their pharmacological relevance at the blood-brain barrier. J Pharm Pharmacol 2001, 53:497-503.

101. Smith QR, Momma S, Aoyagi M, Rapoport SI: Kinetics of neutral amino acid transport across the blood-brain barrier. J Neurochem 1987 49:1651-1658.

102. Stoll J, Wadhwani KC, Smith QR: Identification of the cationic amino acid transporter (System y+) of the rat blood-brain barrier. J Neurochem 1993, 60:1956-1959.

103. Betz AL, Goldstein GW: Polarity of the blood-brain barrier: neutral amino acid transport into isolated brain capillaries. Science 1978, 202:225-226. 
104. Tayarani I, Lefauconnier J-M, Roux F, Bourrer J-M: Evidence for alanine, serine, and cystine system of transport in isolated brain capillaries. J Cereb Blood Flow Metab 1987, 7:585-591.

105. Sánchez del Pino MM, Peterson DR, Hawkins RA: Neutral amino acid transport characterization of isolated luminal and abluminal membranes of the blood-brain barrier. J Biol Chem 1995, 270:14913-14918.

106. Lee WJ, Hawkins RA, Viña JR, Peterson DR: Glutamine transport by the blood-brain barrier: a possible mechanism for nitrogen removal. Am J Physiol Cell Physiol 1998, 274:C1101-C1107.

107. O'Kane RL, Martinez-Lopez I, DeJoseph MR, Viña JR, Hawkins RA: Na (+)-dependent glutamate transporters (EAAT1, EAAT2, and EAAT3) of the blood-brain barrier. A mechanism for glutamate removal. J Biol Chem 1999, 274:31891-31895.

108. Stegink LD, Filer LJ Jr, Baker GL: Plasma amino acid concentrations in normal adults fed meals with added monosodium L-glutamate and aspartame. J Nutr 1983, 113:1851-1860.

109. Benveniste $H$, Drejer J, Schousboe A, Diemer NH: Elevations of the extracellular concentrations of glutamate and aspartate in rat hippocampus during transient cerebral ischemia monitored by intracerebral microdialysis. J Neurochem 1984, 43:1369-1374.

110. Hawkins RA: The blood-brain barrier and glutamate. Am J Clin Nutr 2009, 90:8675-874S.

111. Zlotnik A, Gurevich B, Tkachov S, Maoz I, Shapira Y, Teichberg VI: Brain neuroprotection by scavenging blood glutamate. Exp Neurol 2007 203:213-220.

112. Abbott NJ, Patabendige AA, Dolman DE, Yusof SR, Begley DJ: Structure and function of the blood-brain barrier. Neurobiol Dis 2010, 37:13-25.

113. Segal MB, Preston JE, Collis CS, Zlokovic BV: Kinetics and Na independence of amino acid uptake by blood side of perfused sheep choroid plexus. Am J Physiol 1990, 258:F1288-F1294.

114. Duelli R, Enerson BE, Gerhart DZ, Drewes LR: Expression of large amino acid transporter LAT1 in rat brain endothelium. J Cereb Blood Flow Metab 2000, 20:1557-1562.

115. Preston JE, Segal MB: The uptake of anionic and cationic amino acids by the isolated perfused sheep choroid plexus. Brain Res 1992, 581:351-355.

116. Keep RF, Xiang J: N-system amino acid transport at the blood-CSF barrier. J Neurochem 1995, 65:2571-2576.

117. Agulhon C, Rostaing $P$, Ravassard $P$, Sagné C, Triller A, Giros B: Lysosomal amino acid transporter LYAAT-1 in the rat central nervous system: an in situ hybridization and immunohistochemical study. J Comp Neurol 2003, 462:71-89.

118. Al-Sarraf H, Preston JE, Segal MB: Acidic amino acid accumulation by rat choroid plexus during development. Brain Res Dev Brain Res 1997, 102:47-52

119. Beschorner R, Pantazis G, Jeibmann A, Boy J, Meyermann R, Mittelbronn M, Schittenhelm J: Expression of EAAT-1 distinguishes choroid plexus tumors from normal and reactive choroid plexus epithelium. Acta Neuropathol 2009, 117:667-675.

120. Pellerin E, Magistretti PJ: Food for thought: challenging the dogmas. J Cereb Blood Flow Metab 2003, 23:1282-1286.

121. Adle-Biassette $H$, Olivier $P$, Verney $C$, Fontaine $R H$, Evrard $P$, Hénin $D$ Massias L, Gressens P, Baud O: Cortical consequences of in vivo blockade of monocarboxylate transport during brain development in mice. Pediatr Res 2007, 61:54-60.

122. Poole RC, Halestrap AP: Transport of lactate and other monocarboxylates across mammalian plasma membranes. Am J Physiol 1993, 264: C761-C782.

123. Halestrap AP, Meredith D: The SLC16 gene family: from monocarboxylate transporters (MCTs) to aromatic amino acid transporters and beyond. Pflugers Arch 2004, 447:619-628.

124. Bergersen LH: Is lactate food for neurons? Comparison of monocarboxylate transporter subtypes in brain and muscle. Neuroscience 2007, 145:11-19.

125. Bergersen L, Wærhaug O, Helm J, Thomas M, Laake P, Davies AJ, Wilson MC, Halestrap AP, Ottersen OP: A novel postsynaptic density protein: the monocarboxylate transporter MCT2 is colocalized with delta 2 glutamate receptors in postsynaptic densities of parallel fiber-Purkinje cell synapses. Exp Brain Res 2001, 136:523-534

126. Roberts LM, Woodford K, Zhou M, Black DS, Haggerty JE, Tate EH, Grindstaff KK, Mengesha W, Raman C, Zerangue N: Expression of the thyroid hormone transporters monocarboxylate transporter-8 (SLC16A2) and organic ion transporter-14 (SLCO1C1) at the blood-brain barrier. Endocrinology 2008, 149:6251-6261.

127. Schwartz CE, Stevenson RE: The MCT8 thyroid hormone transporter and Allan-Herndon-Dudley syndrome. Best Pract Res Clin Endocrinol Metab 2007, 21:307-321.

128. Puchowicz MA, Xu K, Sun X, Ivy A, Emancipator D, LaManna JC: Dietinduced ketosis increases capillary density without altered blood flow in rat brain. Am J Physiol Endocrinol Metab 2006, 292:E1607-E1615.

129. Leino RL, Gerhart DZ, Drewes LR: Monocarboxylate transporter (MCT1) abundance in brains of suckling and adult rats: a quantitative electron microscopic immunogold study. Brain Res Dev Brain Res 1999, 113:47-54.

130. Koehler-Stec EM, Simpson IA, Vannucci SJ, Landschulz KT, Landschulz WH: Monocarboxylate transporter expression in mouse brain. Am J Physiol 1998, 275:E516-E524

131. Permanne B, Adessi C, Saborio GP, Fraga S, Frossard MJ, Van Dorpe J, Dewachter I, Banks WA, Van Leuven F, Soto C: Reduction of amyloid load and cerebral damage in a transgenic mouse model of Alzheimer's disease by treatment with a beta-sheet breaker peptide. FASEB J 2002, 16:860-862.

132. Tuszynski MH, Blesch A: Nerve growth factor: from animal models of cholinergic neuronal degeneration to gene therapy in Alzheimer's disease. Prog Brain Res 2004, 146:441-449.

133. Dawbarn D, Allen SJ: Neurotrophins and neurodegeneration. Neuropathol Appl Neurobiol 2003, 29:211-230.

134. Espejo M, Cutillas B, Arenas TE, Ambrosio S: Increased survival of dopaminergic neurons in striatal grafts of fetal ventral mesencephalic cells exposed to neurotrophin-3 or glial cell line-derived neurotrophic factor. Cell Transplant 2000, 9:45-53.

135. Guan J, Krishnamurthi R, Waldvogel HJ, Faull RL, Clark R, Gluckman P: Nterminal tripeptide of IGF-1 (GPE) prevents the loss of TH positive neurons after 6-OHDA induced nigral lesion in rats. Brain Res 2000, 859:286-292.

136. Brasnjevic I, Steinbusch HW, Schmitz C, Martinez-Martinez P: Delivery of peptide and protein drugs over the blood-brain barrier. Prog Neurobiol 2009, 87:212-251.

137. Zlokovic BV, Begley D, Chain DG: Blood-brain barrier permeability to dipeptides and their constituent amino acids. Brain Res 1983, 271:65-71.

138. Rubio-Aliaga I, Daniel $\mathrm{H}$ : Peptide transporters and their roles in physiological processes and drug disposition. Xenobiotica 2008, 38:1022-1042.

139. Zlokovic BV, Hyman S, McComb JG, Lipovac MN, Tang G, Davson H: Kinetics of arginine-vasopressin uptake at the blood-brain barrier. Biochim Biophys Acta 1990, 1025:191-198.

140. Zlokovic BV, Lipovac MN, Begley DJ, Davson H, Rakic L: Transport of leucine-enkephalin across the blood-brain barrier in the perfused guinea pig brain. J Neurochem 1987, 49:310-315.

141. Zlokovic BV, Mackic JB, Djuricic B, Davson H: Kinetic analysis of leucineenkephalin cellular uptake at the luminal side of the blood-brain barrier in an in situ perfused guinea-pig brain. J Neurochem 1989, 53:1333-1340.

142. Zlokovic BV: Cerebrovascular permeability to peptides: manipulations of transport systems at the blood-brain barrier. Pharm Res 1995, 12:1395-1406.

143. Banks WA, Kastin AJ: A brain-to-blood carrier-mediated transport system for small, N-tyrosinated peptides. Pharmacol Biochem Behav 1984, 21:943-946.

144. Banks WA: The CNS as a target for peptides and peptide-based drugs. Expert Opin Drug Deliv 2006, 3:707-712.

145. Dogrukol-Ak D, Kumar VB, Ryerse JS, Farr SA, Verma S, Nonaka N, Nakamachi T, Ohtaki H, Niehoff ML, Edwards JC, Shioda S, Morley JE, Banks WA: Isolation of peptide transport system- 6 from brain endothelial cells: therapeutic effects with antisense inhibition in Alzheimer and stroke models. J Cereb Blood Flow Metab 2009, 29:411-422.

146. Brownlees J, Williams $\mathrm{CH}$ : Peptidases, peptides, and the mammalian blood-brain barrier. J Neurochem 1993, 60:793-803.

147. Banks WA, Kastin AJ: CSF-plasma relationships for DSIP and some other neuropeptides. Pharmacol Biochem Behav 1983, 19:1037-1040.

148. Woods SC, Seeley RJ, Baskin DG, Schwartz MW: Insulin and the bloodbrain barrier. Curr Pharm Des 2003, 9:795-800.

149. Broadwell RD, Baker-Cairns BJ, Friden PM, Oliver C, Villegas JC: Transcytosis of protein through the mammalian cerebral epithelium and 
endothelium. III. Receptor-mediated transcytosis through the bloodbrain barrier of blood-borne transferrin and antibody against the transferrin receptor. Exp Neurol 1996, 142:47-65.

150. Banks WA, Farr SA, La Scola ME, Morley JE: Intravenous human interleukin1alpha impairs memory processing in mice: dependence on blood-brain barrier transport into posterior division of the septum. J Pharmacol Exp Ther 2001, 299:536-541.

151. Zlokovic BV, Jovanovic S, Miao W, Samara S, Verma S, Farrell CL: Differential regulation of leptin transport by the choroid plexus and blood-brain barrier and high affinity transport systems for entry into hypothalamus and across the blood-cerebrospinal fluid barrier. Endocrinology 2000, 141:1434-1441.

152. Banks WA, Farrell CL: Impaired transport of leptin across the blood-brain barrier in obesity is acquired and reversible. Am J Physiol Endocrinol Metab 2003, 285:E10-E15.

153. Deane R, Sagare A, Hamm K, Parisi M, LaRue B, Guo H, Wu Z, Holtzman DM, Zlokovic BV: IgG-assisted age-dependent clearance of Alzheimer's amyloid beta peptide by the blood-brain barrier neonatal Fc receptor. J Neurosci 2005, 25:11495-11503.

154. Nishijima T, Piriz J, Duflot S, Fernandez AM, Gaitan G, Gomez-Pinedo U, Verdugo JM, Leroy F, Soya H, Nuñez A, Torres-Aleman I: Neuronal activity drives localized blood-brain-barrier transport of serum insulin-like growth factor-I into the CNS. Neuron 2010, 67:834-846.

155. Biere AL, Ostaszewski B, Stimson ER, Hyman BT, Maggio JE, Selkoe DJ: Amyloid beta-peptide is transported on lipoproteins and albumin in human plasma. J Biol Chem 1996, 271:32916-32922.

156. Calero M, Rostagno A, Matsubara E, Zlokovic B, Frangione B, Ghiso J: Apolipoprotein J (clusterin) and Alzheimer's disease. Microsc Res Tech 2000, 50:305-315.

157. Sagare A, Deane R, Bell RD, Johnson B, Hamm K, Pendu R, Marky A, Lenting PJ, Wu Z, Zarcone T, Goate A, Mayo K, Perlmutter D, Coma M, Zhong Z, Zlokovic BV: Clearance of amyloid-beta by circulating lipoprotein receptors. Nat Med 2007, 13:1029-1031.

158. Deane R, Bell RD, Sagare A, Zlokovic BV: Clearance of amyloid-beta peptide across the blood-brain barrier: implication for therapies in Alzheimer's disease. CNS Neurol Disord Drug Targets 2009, 8:16-30.

159. Yan SF, Ravichandran R, Schmidt AM: The RAGE axis: a fundamental mechanism signaling danger to the vulnerable vasculature. Circ Res 2010, 106:842-853

160. Zlokovic BV, Deane R, Sagare AP, Bell RD, Winkler EA: Low density lipoprotein receptor related protein-1: A serial clearance homeostatic mechanism controlling Alzheimer's amyloid $\beta$-peptide elimination from the brain. J Neurochem 2010, 115:1077-1089.

161. Deane R, Wu Z, Sagare A, Davis J, Du Yan S, Hamm K, Xu F, Parisi M, LaRue B, Hu HW, Spijkers P, Guo H, Song X, Lenting PJ, Van Nostrand WE, Zlokovic BV: LRP/amyloid b-peptide interaction mediates differential brain efflux of Ab isoforms. Neuron 2004, 43:333-344.

162. Bell RD, Sagare AP, Friedman AE, Bedi GS, Holtzman DM, Deane R, Zlokovic BV: Transport pathways for clearance of human Alzheimer's amyloid beta-peptide and apolipoproteins $\mathrm{E}$ and $\mathrm{J}$ in the mouse central nervous system. J Cereb Blood Flow Metab 2007, 27:909-918.

163. Ito S, Ueno T, Ohtsuki S, Terasaki T: Lack of brain-to-blood efflux transport activity of low-density lipoprotein receptor-related protein-1 (LRP-1) for amyloid-b peptide(1-40) in mouse: involvement of an LRP-1independent pathway. J Neurochem 2010, 113:1356-1363.

164. Banks WA: Delivery of peptides to the brain: emphasis on therapeutic development. Biopolymers 2008, 90:589-594.

165. Broadwell RD: Transcytosis of macromolecules through the blood-brain barrier: a cell biological perspective and critical appraisal. Acta Neuropathol 1989, 79:117-128.

166. Bodor N, Buchwald P: Brain-targeted drug delivery: experiences to date. Am J Drug Deliv 2003, 1:13-26.

167. Levin VA: Relationship of octanol/water partition coefficient and molecular weight to rat brain capillary permeability. J Med Chem 1980, 23:682-684.

168. Banks WA, Kastin AJ: Editorial review: Peptide transport systems for opiates across the blood- brain barrier. Am J Physiol 1990, 259:E1-E10.

169. King M, Su W, Chang A, Zuckerman A, Pasternak GW: Transport of opioids from the brain to the periphery by P-glycoprotein: peripheral actions of central drugs. Nat Neurosci 2001, 4:221-222.
170. Boado RJ, Zhang Y, Wang Y, Pardridge WM: Engineering and expression of a chimeric transferrin receptor monoclonal antibody for bloodbrain barrier delivery in the mouse. Biotechnol Bioeng 2009, 102:1251-1258.

171. van Rooy I, Cakir-Tascioglu S, Couraud PO, Romero IA, Weksler B, Storm G, Hennink WE, Schiffelers RM, Mastrobattista E: Identification of peptide ligands for targeting to the blood-brain barrier. Pharm Res 2010, 27:673-682.

172. Szmydynger-Chodobska J, Fox LM, Lynch KM, Zink BJ, Chodobski A: Vasopressin amplifies the production of proinflammatory mediators in traumatic brain injury. J Neurotrauma 2010, 27:1449-1461.

173. Ocheltree SM, Shen H, Hu Y, Xiang J, Keep RF, Smith DE: Role of PEPT2 in the choroid plexus uptake of glycylsarcosine and 5-aminolevulinic acid: studies in wild-type and null mice. Pharm Res 2004, 21:1680-1685.

174. Yamashita T, Shimada S, Guo W, Sato K, Kohmura E, Hayakawa T, Takagi T, Tohyama M: Cloning and functional expression of a brain peptide/ histidine transporter. J Biol Chem 1997, 272:10205-10211.

175. Ocheltree SM, Shen H, Hu Y, Keep RF, Smith DE: Role and relevance of peptide transporter 2 (PEPT2) in the kidney and choroid plexus: in vivo studies with glycylsarcosine in wild-type and PEPT2 knockout mice. J Pharmacol Exp Ther 2005, 315:240-247.

176. Shu C, Shen H, Teuscher NS, Lorenzi PJ, Keep RF, Smith DE: Role of PEPT2 in peptide/mimetic trafficking at the blood-cerebrospinal fluid barrier: studies in rat choroid plexus epithelial cells in primary culture. J Pharmacol Exp Ther 2002, 301:820-829.

177. Berger UV, Hediger MA: Distribution of peptide transporter PEPT2 mRNA in the rat nervous system. Anat Embryol (Berl) 1999, 199:439-449.

178. Dietrich MO, Spuch C, Antequera D, Rodal I, de Yébenes JG, Molina JA, Bermejo F, Carro E: Megalin mediates the transport of leptin across the blood-CSF barrier. Neurobiol Aging 2008, 29:902-912.

179. Alvira-Botero X, Carro EM: Clearance of amyloid- peptide across the choroid plexus in Alzheimer's disease. Curr Aging Sci 2010.

180. Behl M, Zhang Y, Shi Y, Cheng J, Du Y, Zheng W: Lead-induced accumulation of beta-amyloid in the choroid plexus: role of low density lipoprotein receptor protein-1 and protein kinase C. Neurotoxicology 2010, 31:524-532.

181. Johanson CE, Duncan JA, Klinge PM, Brinker T, Stopa EG, Silverberg GD: Multiplicity of cerebrospinal fluid functions: New challenges in health and disease. Cerebrospinal Fluid Res 2008, 5:10.

182. Johanson CE, Donahue JE, Spangenberger A, Stopa EG, Duncan JA, Sharma HS: Atrial natriuretic peptide: its putative role in modulating the choroid plexus-CSF system for intracranial pressure regulation. Acta Neurochir Suppl 2006, 96:451-456.

183. Mori K, Tsutsumi K, Kurihara M, Kawaguchi T, Niwa M: Alteration of atrial natriuretic peptide receptors in the choroid plexus of rats with induced or congenital hydrocephalus. Childs Nerv Syst 1990, 6:190-193.

184. Chodobski A, Loh YP, Corsetti S, Szmydynger-Chodobska J, Johanson CE, Lim YP, Monfils PR: The presence of arginine vasopressin and its mRNA in rat choroid plexus epithelium. Brain Res Mol Brain Res 1997, 48:67-72.

185. Szmydynger-Chodobska J, Chung I, Chodobski A: Chronic hypernatremia increases the expression of vasopressin and voltage-gated Na channels in the rat choroid plexus. Neuroendocrinology 2006, 84:339-345.

186. Chodobski A, Szmydynger-Chodobska J, Johanson CE: Vasopressin mediates the inhibitory effect of central angiotensin II on cerebrospinal fluid formation. Eur J Pharmacol 1998, 347:205-209.

187. Johanson CE, Preston JE, Chodobski A, Stopa EG, Szmydynger-Chodobska J, McMillan PN: AVP V1 receptor-mediated decrease in Cl- efflux and increase in dark cell number in choroid plexus epithelium. Am J Physiol 1999, 276:C82-C90

188. Johanson C, Stopa E, Baird A, Sharma H: Traumatic brain injury and recovery mechanisms: peptide modulation of periventricular neurogenic regions by the choroid plexus-CSF nexus. J Neural Transm 2010.

189. Schreiber $\mathrm{G}$ : The evolution of transthyretin synthesis in the choroid plexus. Clin Chem Lab Med 2002, 40:1200-1210.

190. Palha JA, Hays MT, de Escobar GM, Episkopou V, Gottesman ME, Saraiva MHM: Transthyretin is not essential for thyroxine to reach the brain and other tissues in transthyretin-null mice. Am J Physiol 1997, 272: E485-E493.

191. Quintela T, Alves CH, Gonçalves I, Baltazar G, Saraiva MJ, Santos CR: 5Alphadihydrotestosterone up-regulates transthyretin levels in mice and rat 
choroid plexus via an androgen receptor independent pathway. Brain Res 2008, 1229:18-26.

192. Tang YP, Haslam SZ, Conrad SE, Sisk CL: Estrogen increases brain expression of the mRNA encoding transthyretin, an amyloid beta scavenger protein. J Alzheimers Dis 2004, 6:413-420.

193. Quintela T, Gonçalves I, Baltazar G, Alves CH, Saraiva MJ, Santos CR: 17betaestradiol induces transthyretin expression in murine choroid plexus via an oestrogen receptor dependent pathway. Cell Mol Neurobiol 2009, 29:475-483.

194. Quintela T, Gonçalves I, Martinho A, Alves CH, Saraiva MJ, Rocha P, Santos CR: Progesterone enhances transthyretin expression in the rat choroid plexus in vitro and in vivo via progesterone receptor. $J \mathrm{Mol}$ Neurosci 2010.

195. Schinkel AH, Jonker JW: Mammalian drug efflux transporters of the ATP binding cassette $(A B C)$ family: an overview:. Adv Drug Deliv Rev 2003, 55:3-29.

196. Sauna ZE, Smith MM, Muller M, Kerr KM, Ambudkar SM: The mechanism of action of multidrug-resistance- linked P-glycoprotein. J Bioenerg Biomembranes 2001, 33:481-491.

197. Russel FG, Masereeuw R, van Aubel RA: Molecular aspects of renal anionic drug transport. Ann Rev Physiol 2002, 64:563-594.

198. Dresser MJ, Leabman MK, Giacomini KM: Transporters involved in the elimination of drugs in the kidney: organic anion transporters and organic cation transporters. J Pharm Sci 2001, 90:397-421.

199. Roberts LM, Black DS, Raman C, Woodford K, Zhou M, Haggerty JE, Yan AT, Cwirla SE, Grindstaff KK: Subcellular localization of transporters along the rat blood-brain barrier and blood-cerebral-spinal fluid barrier by in vivo biotinylation. Neuroscience 2008, 155:423-438.

200. Babakhanian K, Bendayan M, Bendayan R: Localization of P-glycoprotein at the nuclear envelope of rat brain cells. Biochem Biophys Res Commun 2007, 361:301-306.

201. Schinkel A, Mayer U, Wagenaar E, Mol C, van Deemter L, Smit J, van der Valk MA, Voordouw AC, Spits H, van Tellingen O, Zijlmans JM, Fibbe WE, Borst P: Normal viability and altered pharmacokinetics in mice lacking mdr1-type (drug-transporting) P-glycoproteins. Proc Natl Acad Sci USA 1997, 94:4028-4033.

202. Linnet $K$, Ejsing T: A review on the impact of P-glycoprotein on the penetration of drugs into the brain. Focus on psychotropic drugs. Eur Neuropsychopharmacol 2008, 18:157-169.

203. Miller DS: Regulation of P-glycoprotein and other ABC drug transporters at the blood-brain barrier. Trends Pharmacol Sci 2010, 31:246-54.

204. Eyal S, Hsiao P, Unadkat JD: Drug interactions at the blood-brain barrier: fact or fantasy? Pharmacol Ther 2009, 123:80-104.

205. Calatozzolo C, Gelati M, Ciusani E, Sciacca F, Pollo B, Cajola L, Marras C, Silvani A, Vitellaro-Zuccarello L, Croci D, Boiardi A, Salmaggi A: Expression of drug resistance proteins Pgp, MRP1, MRP3, MRP5 and GST-pi in human glioma. J Neurooncol 2005, 74:113-121

206. Zhang W, Mojsilovic-Petrovic J, Andrade M, Zhang H, Ball M, Stanimirovic D: The expression and functional characterization of $A B C G 2$ in brain endothelial cells and vessels. FASEB J 2003, 17:2085-2087.

207. Dauchy S, Dutheil F, Weaver R, Chassoux F, Daumas-Duport C, Couraud P, Scherrmann JM, De Waziers I, Declèves X: ABC transporters, cytochromes $\mathrm{P} 450$ and their main transcription factors: expression at the human blood-brain barrier. J Neurochem 2008, 107:1518-1528.

208. Westholm D, Rumbley J, Salo D, Rich T, Anderson G: Organic aniontransporting polypeptides at the blood-brain and blood-cerebrospinal fluid barriers. Curr Top Dev Biol 2008, 80:135-170.

209. Bronger H, König J, Kopplow K, Steiner H, Ahmadi R, Herold-Mende C, Keppler D, Nies AT: ABCC drug efflux pumps and organic anion uptake transporters in human gliomas and the blood- tumor barrier. Cancer Res 2005, 65:11419-11428.

210. Mori S, Ohtsuki S, Takanaga H, Kikkawa T, Kang Y, Terasaki T: Organic anion transporter 3 is involved in the brain-to-blood efflux transport of thiopurine nucleobase analogs. J Neurochem 2004, 90:931-941.

211. Alebouyeh M, Takeda M, Onozato M, Tojo A, Noshiro R, Hasannejad H, Inatomi J, Narikawa S, Huang XL, Khamdang S, Anzai N, Endou H: Expression of human organic anion transporters in the choroid plexus and their interactions with neurotransmitter metabolites. J Pharmacol Sci 2003, 93:430-436.
212. Koepsell H, Lips K, Volk C: Polyspecific organic cation transporters: structure, function, physiological roles, and biopharmaceutical implications. Pharm Res 2007, 24:1227-1251.

213. Miecz D, Januszewicz E, Czeredys M, Hinton B, Berezowski V, Cecchelli R, Nałecz KA: Localization of organic cation/carnitine transporter (OCTN2) in cells forming the blood-brain barrier. J Neurochem 2008, 104:113-123.

214. Strazielle N, Khuth ST, Ghersi-Egea JF: Detoxification systems, passive and specific transport for drugs at the blood-CSF barrier in normal and pathological situations. Adv Drug Deliv Rev 2004, 56:1717-1740.

215. Daood M, Tsai C, Ahdab-Barmada M, Watchko J: ABC Transporter (P-gp/ $A B C B 1, M R P 1 / A B C C 1, B C R P / A B C G 2)$ Expression in the Developing Human CNS. Neuropediatrics 2008, 39:211-218.

216. Rao W, Dahlheimer JL, Bardgett ME, Snyder AZ, Finch RA, Sartorelli AC, Piwnica-Worms D: Choroid plexus epithelial expression of MDR1 P glycoprotein and multidrug resistance-associated protein contribute to the blood-cerebrospinal-fluid drug-permeability barrier. Proc Natl Acad Sci USA 1999, 96:3900-3905.

217. Gazzin S, Strazielle N, Schmitt C, Fevre-Montange M, Ostrow JD, Tiribelli C, Ghersi-Egea JF: Differential expression of the multidrug resistance-related proteins $A B C b 1$ and $A B C c 1$ between blood-brain interfaces. J Comp Neurol 2008, 510:497-507.

218. Nies A, Jedlitschky G, König J, Herold-Mende C, Steiner H, Schmitt H, Keppler D: Expression and immunolocalization of the multidrug resistance proteins, MRP1-MRP6 (ABCC1-ABCC6), in human brain. Neuroscience 2004, 129:349-360

219. Lee YJ, Kusuhara H, Sugiyama Y: Do multidrug resistance-associated protein- 1 and -2 play any role in the elimination of estradiol- 17 betaglucuronide and 2, 4-dinitrophenyl-S-glutathione across the bloodcerebrospinal fluid barrier? J Pharm Sci 2004, 93:99-107.

220. Tachikawa M, Watanabe M, Hori S, Fukaya M, Ohtsuki S, Asashima T, Terasaki T: Distinct spatio-temporal expression of ABCA and ABCG transporters in the developing and adult mouse brain. J Neurochem 2005, 95:294-304.

221. Gao B, Stieger B, Noe B, Fritschy JM, Meier PJ: Localization of the organic anion transporting polypeptide 2 (Oatp2) in capillary endothelium and choroid plexus epithelium of rat brain. J Histochem Cytochem 1999, 47:1255-1264.

222. Kusuhara H, He Z, Nagata Y, Nozaki Y, Ito T, Masuda H, Meier PJ, Abe T, Sugiyama $Y$ : Expression and functional involvement of organic anion transporting polypeptide subtype 3 (SIc21a7) in rat choroid plexus. Pharm Res 2003, 20:720-727.

223. Zhang H, Song YN, Liu WG, Guo XL, Yu LG: Regulation and role of organic anion-transporting polypeptides (OATPs) in drug delivery at the choroid plexus. J Clin Neurosci 2010, 17:679-684.

224. Choudhuri S, Cherrington NJ, Li N, Klaassen CD: Constitutive expression of various xenobiotic and endobiotic transporter mRNAs in the choroid plexus of rats. Drug Metab Dispos 2003, 31:1337-1345.

225. Nagata $Y$, Kusuhara $H$, Endou H, Sugiyama $Y$ : Expression and functional characterization of rat organic anion transporter 3 (rOat3) in the choroid plexus. Mol Pharmacol 2002, 61:982-988.

226. Bauer B, Hartz AM, Fricker G, Miller DS: Pregnane $\times$ receptor up-regulation of Pglycoprotein expression and transport function at the blood-brain barrier. Mol Pharmacol 2004, 66:413-419.

227. Bauer B, Yang X, Hartz AM, Olson ER, Zhao R, Kalvass JC, Pollack GM, Miller DS: In vivo activation of human pregnane $x$ receptor tightens the blood-brain barrier to methadone through P-glycoprotein up-regulation. Mol Pharmacol 2006, 70:1212-1219.

228. Roberts DJ, Goralski KB: A critical overview of the influence of inflammation and infection on P-glycoprotein expression and activity in the brain. Expert Opin Drug Metab Toxicol 2008, 4:1245-1264.

229. Bauer B, Hartz AM, Miller DS: Tumor necrosis factor alpha and endothelin1 increase P-glycoprotein expression and transport activity at the bloodbrain barrier. Mol Pharmacol 2007, 71:667-675.

230. Hartz AM, Bauer B, Fricker G, Miller DS: Rapid modulation of P-glycoproteinmediated transport at the blood-brain barrier by tumor necrosis factoralpha and lipopolysaccharide. Mol Pharmacol 2006, 69:462-470.

231. Hartz AM, Bauer B, Block ML, Hong JS, Miller DS: Diesel exhaust particles induce oxidative stress, proinflammatory signaling, and P-glycoprotein up-regulation at the blood-brain barrier. FASEB J 2008, 22:2723-2733. 
232. Block ML, Wu X, Pei Z, Li G, Wang T, Qin L, Wilson B, Yang J, Hong JS, Veronesi B: Nanometer size diesel exhaust particles are selectively toxic to dopaminergic neurons: the role of microglia, phagocytosis, and NADPH oxidase. FASEB J 2006, 18:1618-1620.

233. Tai LM, Loughlin AJ, Male DK, Romero IA: P-Glycoprotein and breast cancer resistance protein restrict apical-to-basolateral permeability of human brain endothelium to amyloid-beta. J Cereb Blood Flow Metab 2009, 29:1079-1083.

234. Xiong H, Callaghan D, Jones A, Bai J, Rasquinha I, Smith C, Pei K, Walker D, Lue LF, Stanimirovic D, Zhang W: ABCG2 is upregulated in Alzheimer's brain with cerebral amyloid angiopathy and may act as a gatekeeper at the blood-brain barrier for Ab(1-40) peptides. J Neurosci 2009 29:5463-5475.

235. Vogelgesang S, Cascorbi I, Schroeder E, Pahnke J, Kroemer HK, Siegmund W, Kunert-Keil C, Walker LC, Warzok RW: Deposition of Alzheimer's beta-amyloid is inversely correlated with P-glycoprotein expression in the brains of elderly non-demented humans. Pharmacogenetics 2002, 12:535-541.

236. Wijesuriya HC, Bullock JY, Faull RL, Hladky SB, Barrand MA: ABC efflux transporters in brain vasculature of Alzheimer's subjects. Brain Res 2010 1358:228-238

237. Abbott NJ: Evidence for bulk flow of brain interstitial fluid: significance for physiology and pathology. Neurochem Int 2004, 45:545-552.

238. Cserr HF, DePasquale M, Patlak CS, Pullen RGL: Convection of cerebral interstitial fluid and its role in brain volume regulation. Ann N Y Acad Sci 1989, 481:123-134

239. Vorbrodt AW: Ultrastructural cytochemistry of blood-brain barrier endothelia. Prog Histochem Cytochem 1988, 18:1-99.

240. Zlokovic BV, Mackic JB, Wang L, McComb JG, McDonough A: Differential expression of $\mathrm{Na}$, K-ATPase alpha and beta subunit isoforms at the blood-brain barrier and the choroid plexus. J Biol Chem 1993, 268:8019-8025.

241. Lingrel JB: The physiological significance of the cardiotonic steroid/ ouabain-binding site of the Na, K-ATPase. Annu Rev Physiol 2010, 72:395-412.

242. O'Donnell ME, Lam TI, Tran LQ: Estradiol reduces activity of the bloodbrain barrier $\mathrm{Na}-\mathrm{K}-\mathrm{Cl}$ cotransporter and decreases edema formation in permanent middle cerebral artery occlusion. J Cereb Blood Flow Metab 2006, 26:1234-1249.

243. Yang T, Roder KE, Bhat GJ, Thekkumkara TJ, Abbruscato TJ: Protein kinase C family members as a target for regulation of blood-brain barrier $\mathrm{Na}, \mathrm{K}$, $2 \mathrm{Cl}$-cotransporter during in vitro stroke conditions and nicotine exposure. Pharm Res 2006, 23:291-302.

244. Millar ID, Brown PD: NBCe2 exhibits a $3 \mathrm{HCO}-: 1 \mathrm{Na}+$ stoichiometry in mouse choroid plexus epithelial cells. Biochem Biophys Res Commun 2008, 373:550-554

245. Taylor CJ, Nicola PA, Wang S, Barrand MA, Hladky SB: Transporters involved in regulation of intracellular $\mathrm{pH}$ in primary cultured rat brain endothelial cells. J Physiol 2006, 576:769-785.

246. Vigne $\mathrm{P}$, Farre $\mathrm{AL}$, Frelin $\mathrm{C}$ : $\mathrm{Na}+\mathrm{K}+-\mathrm{Cl}-$ cotransporter of brain capillary endothelial cells. J Biol Chem 1994, 269:19925-19930.

247. Nicola PA, Taylor CJ, Wang S, Barrand MA, Hladky SB: Transport activities involved in intracellular $\mathrm{pH}$ recovery following acid and alkali challenges in rat brain microvascular endothelial cells. Pflugers Arch 2008, 456:801-812

248. Johanson CE, Duncan JA, Klinge PM, Brinker T, Stopa EG, Silverberg GD: Multiplicity of cerebrospinal fluid functions: New challenges in health and disease. Cerebrospinal Fluid Res 2008, 5:10.

249. Pollay M, Curl F: Secretion of cerebrospinal fluid by the ventricular ependyma of the rabbit. Am J Physiol 1967, 213:1031-1038.

250. Damkier HH, Brown PD, Praetorius J: Epithelial pathways in choroid plexus electrolyte transport. Physiology (Bethesda) 2010, 25:239-249.

251. Praetorius J, Nejsum LN, Nielsen S: A SCL4A10 gene product maps selectively to the basolateral plasma membrane of choroid plexus epithelial cells. Am J Physiol Cell Physiol 2004, 286:C601-C610.

252. Jacobs S, Ruusuvuori E, Sipila ST, Haapanen A, Damkier HH, Kurth I, Hentschke M, Schweizer M, Rudhard Y, Laatikainen LM, Tyynela J, Praetorius J, Voipio J, Hübner CA: Mice with targeted Slc4a10 gene disruption have small brain ventricles and show reduced neuronal excitability. Proc Natl Acad Sci USA 2007, 105:311-316.
253. Praetorius J, Nielsen S: Distribution of sodium transporters and aquaporin-1 in the human choroid plexus. Am J Physiol Cell Physiol 2006, 291:C59-C67.

254. Damkier $\mathrm{HH}$, Prasad $\mathrm{V}$, Hubner $\mathrm{CA}$, Praetorius J: Nhe1 is a luminal $\mathrm{Na}+/ \mathrm{H}+$ exchanger in mouse choroid plexus and is targeted to the basolateral membrane in Ncbe/Nbcn2-null mice. Am J Physiol Cell Physiol 2009, 296: C1291-C1300

255. Keep RF, Xiang J, Betz AL: Potassium cotransport at the rat choroid plexus. Am J Physiol Cell Physiol 1994, 267:C1616-C1622.

256. Hughes AL, Pakhomova A, Brown PD: Regulatory volume increase in epithelial cells isolated from the mouse fourth ventricle choroid plexus involves $\mathrm{Na}+-\mathrm{H}+$ exchange but not $\mathrm{Na}+-\mathrm{K}+-2 \mathrm{Cl}-$ cotransport. Brain Res 2010, 1323:1-10.

257. Redzic ZB, Isakovic AJ, Misirlic Dencic ST, Popadic D, Segal MB: Uneven distribution of nucleoside transporters and intracellular enzymatic degradation prevent transport of intact $\left[{ }^{14} \mathrm{C}\right]$ adenosine across the sheep choroid plexus epithelium as a monolayer in primary culture. Cerebrospinal Fluid Res 2006, 3:4.

doi:10.1186/2045-8118-8-3

Cite this article as: Redzic: Molecular biology of the blood-brain and the blood-cerebrospinal fluid barriers: similarities and differences. Fluids and Barriers of the CNS 2011 8:3.

\section{Submit your next manuscript to BioMed Central and take full advantage of:}

- Convenient online submission

- Thorough peer review

- No space constraints or color figure charges

- Immediate publication on acceptance

- Inclusion in PubMed, CAS, Scopus and Google Scholar

- Research which is freely available for redistribution

Submit your manuscript at www.biomedcentral.com/submit
C) Biomed Central 